\title{
ALKALI TREATMENT OF MICROROUGH TITANIUM SURFACES AFFECTS MACROPHAGE/MONOCYTE ADHESION, PLATELET ACTIVATION AND ARCHITECTURE OF BLOOD CLOT FORMATION
}

\author{
Vincent Milleret ${ }^{1, \$}$, Stefano Tugulu ${ }^{2, \$}$, Falko Schlottig ${ }^{2}$ and Heike Hall ${ }^{1, *}$ \\ ${ }^{1}$ Cells and BioMaterials, Department of Materials, ETH Zurich, Zürich, Switzerland \\ ${ }^{2}$ Thommen Medical AG, Waldenburg, Switzerland \\ §Both authors contributed equally to this paper
}

\begin{abstract}
Titanium implants are most commonly used for bone augmentation and replacement due to their favorable osseointegration properties. Here, hyperhydrophilic sand-blasted and acid-etched (SBA) titanium surfaces were produced by alkali treatment and their responses to partially heparinized whole human blood were analyzed. Blood clot formation, platelet activation and activation of the complement system was analyzed revealing that exposure time between blood and the material surface is crucial as increasing exposure time results in higher amount of activated platelets, more blood clots formed and stronger complement activation. In contrast, the number of macrophages/monocytes found on alkali-treated surfaces was significantly reduced as compared to untreated SBA Ti surfaces. Interestingly, when comparing untreated to modified SBA Ti surfaces very different blood clots formed on their surfaces. On untreated Ti surfaces blood clots remain thin (below $15 \mathrm{~mm}$ ), patchy and non-structured lacking large fibrin fiber networks whereas blood clots on differentiated surfaces assemble in an organized and layered architecture of more than $30 \mathrm{~mm}$ thickness. Close to the material surface most nucleated cells adhere, above large amounts of non-nucleated platelets remain entrapped within a dense fibrin fiber network providing a continuous cover of the entire surface. These findings might indicate that, combined with findings of previous in vivo studies demonstrating that alkali-treated SBA Ti surfaces perform better in terms of osseointegration, a continuous and structured layer of blood components on the blood-facing surface supports later tissue integration of an endosseous implant.
\end{abstract}

Keywords: SBA Ti surfaces, alkali treatment, hemocompatibility, blood clot formation, fibrin fibers, platelet activation.

*Address for correspondence:

Heike Hall

Cells and BioMaterials

Department of Materials, ETH Zürich

Wolfgang Pauli Strasse 10, HCI E415

8093 Zurich, Switzerland

Telephone Number: ++ 41446336975

FAX Number: ++ 41446321072

E-mail: heike.hall@mat.ethz.ch
Introduction

Immediately upon implantation medical implants get exposed to the patient's blood and surface interactions between blood components such as blood cells and fibrin(ogen) will influence the extent of blood coagulation, fibrin fiber formation and acute inflammation (Anderson, 2001; Arvidsson et al., 2007). Activation of these processes might directly trigger the extrinsic coagulation cascade induced by the trauma of the implantation. Since all cascades of blood coagulation are highly interlinked and proceed in a sequential manner, also contact activation of the intrinsic blood-clotting cascade induced by the cleavage of prekallikrein to kallikrein might be induced after implant implantation. Moreover, complement activation and the activation of platelets and leukocytes on an implant surface has been described extensively (Griffin, 1978; Smith et al., 2003; Jackson, 2007). The chemistry and topography of the medical implant surfaces were demonstrated to be able to influence interactions with all blood components (Smith et al., 2003; Gorbet and Sefton, 2004). Hence the extent and overall success of a medical implant designed e.g. for bone fixation might be directly influenced by the physicochemical properties of the implant surface (Gorbet and Sefton, 2004; Stanford, 2010).

Titanium (Ti), which is currently considered as the material of choice for manufacturing of load-bearing endosseous implants, has been reported to be highly thrombogenic - being one of the reasons for the materials outstanding osseointegrative characteristics (Hong et al., 1999). Recently, Ti implants with superhydrophilic microrough surfaces have attracted much interest due to their superb osseointegrative potential (Schwarz et al., 2009). Superhydrophilic implants have shown to result in enlarged bone to implant contact area and stronger mechanical fixation in the early healing phase of up to 4 weeks post implantation (Buser et al., 2004). In previous studies conversion of hydrophobic to superhydrophilic microrough sand-blasted and acid-etched (SBA) Ti implants was obtained by alkali treatment. Preliminary studies demonstrated stronger osseointegrative potential of alkali-treated microrough SBA Ti implants in vivo (Calvo-Guirado et al., 2010; Stadlinger et al., 2009). Surface analysis indicated that superhydrophilicity of alkali-treated microrough SBA Ti surfaces might at least partly be attributed to deprotonation and ion exchange of hydroxyl-groups on the $\mathrm{TiO}_{2}$-x surfaces increasing the ionic character and the net negative surface charge (Tugulu et al., 2010). Also, Kokubo and colleagues investigated the effect of alkali- and heat-treatment on Tantalum surfaces' 
osseointegration and showed that bone bonding to plates implanted into rabbit tibiae was greater for heat- and alkalitreated tantalum implants compared to native ones. The aim of this contribution is to correlate these changes in the surface chemistry of $\mathrm{TiO}_{2}$-x surfaces with changes in blood clot formation, differential adhesion and activation of blood cells. In order to do so microrough SBA Ti implant surfaces were alkali-treated and then exposed to whole human blood for different exposure times. The activation of the coagulation cascade, the complement system and platelet activation in partially heparinized $(3 \mathrm{IU} / \mathrm{mL})$ whole human blood was assessed by determining the concentration of specific marker proteins after contact with alkali-treated and untreated SBA Ti implant surfaces. The activation of the complement system was assessed by the increase in anaphylatoxin C5a (Gardinali et al., 1992); blood coagulation was determined by an increase in kallikreinlike activity (Griffin and Cochrane, 1976) and the increase in thrombin-antithrombin complexes (TAT) (Diquélou et al., 1994). Activation of platelets was demonstrated by the release of P-selectin and immunohistological staining against CD62p (Matowicka-Karna et al., 2006). Moreover, differential adhesion and activation of monocytes/ macrophages was analyzed by immunohistological staining against CD14 (Ziegler-Heitbrock and Ulevitch, 1993). The second part of the study describes effects of alkali treatment on composition, structure and organization of "in vitro blood clots" formed on SBA Ti implant surfaces.

\section{Materials and Methods}

\section{Preparation of titanium surfaces}

Disk-shaped Ti surfaces of $15 \mathrm{~mm}$ in diameter and 2 $\mathrm{mm}$ thickness composed of titanium grade 4 (Dynamet Incorporated, Washington, PA, USA) were prepared, sandblasted, acid-etched (SBA) and alkali-treated when necessary as previously described (Tugulu et al., 2010). Alkali treatment was performed by sonicating the $\mathrm{Ti}$ surfaces in $0.05 \mathrm{M}$ aqueous $\mathrm{NaOH}$ for $30 \mathrm{~s}$ at room temperature. Ti surfaces were immediately used after alkali treatment.

\section{Partially heparinized whole human blood}

Human whole blood from healthy volunteers not taking medication was purchased from the local blood bank (Zentrale Blutbank, University Hospital Zürich) and was heparinized directly upon withdrawal by using $7 \mathrm{~mL}$ vacutainer tubes (BD Vacutainer ${ }^{\mathrm{TM}}$ No Additive $(\mathrm{Z})$ Plus Tubes; BD, Franklin Lakes, NJ, USA) modified with 21 IU sodium heparin (Carl Roth, Karlsruhe, Germany, Eur. Ph., $120 \mathrm{IU} / \mathrm{mg}$ ) resulting in a final concentration of $3 \mathrm{IU}$ heparin/mL blood. All blood samples used for the experiments were freshly withdrawn, transported and stored at room temperature and not older than $4 \mathrm{~h}$ when used.

\section{Slide chamber, blood incubation and preparation of samples}

Alkali-treated and untreated SBA Ti surfaces were incubated with partially heparinized whole human blood within a rotating slide chamber similar to that described by Hong et al. (Hong et al., 1998). In brief glass, teflon or Ti disks were assembled on both sides of a teflon ring of 12 $\mathrm{mm}$ inner diameter and $10 \mathrm{~mm}$ height and clamped between two stainless steel plates creating a circular chamber of a final volume of $1.1 \mathrm{~mL}$. The closed chambers were filled with blood through a syringe port and incubated for $10 \mathrm{~min}$ or $2 \mathrm{~h}$ under rotation at $6.6 \mathrm{rpm}$ in an incubator (B6030, Heraeus, Hanau, Germany) at $37^{\circ} \mathrm{C}$.

For analysis of protein markers before and after incubation the blood was collected and EDTA was added to a final concentration of $5 \mathrm{mM}$. Subsequently the blood was centrifuged for $10 \mathrm{~min}$ at 2,000 $\mathrm{g}$ at room temperature and the supernatants were collected and stored at $-20{ }^{\circ} \mathrm{C}$ until further analysis.

\section{Enzyme linked immunoassays (ELISA) for the detection of C5a, soluble P-selectin and thrombin- antithrombin (TAT)}

Concentrations of C5a, soluble P-selectin (sP-selectin) and thrombin-antithrombin III (TAT) complexes were determined in partially heparinized $(3 \mathrm{IU} / \mathrm{mL}$ ) whole human blood prepared as described above using commercially available ELISA kits to detect C5a ELISA (from IBL, No. IB 79153), for human sP-Selectin/CD62P immunoassay (from R\&D Systems, Minneapolis, MN, USA; No. BBE6) and for TAT complexes the AssayMax Human Thrombin-antithrombin (TAT) Complexes ELISA Kit from Gentaur (Kampenhout, Belgium) (No. ET1020d) was used, respectively. Kallikrein-like activity was assessed photometrically in plasma derived from partially heparinized whole human blood according to a procedure described by Gallimore et al. (Gallimore and Friberger, 1982) using a substrate reagent from Diapharma (West Chester, OH, USA) (plasma kallikrein-like activity, No S-2302). All assays were carried out according to the manufacturer's instructions and with reagents provided by the manufacturers. The experiments were performed at least 5 times in duplicates.

\section{Scanning electron microscopy (SEM)}

SBA Ti surfaces were analyzed by SEM before and after 10 min and $2 \mathrm{~h}$ of incubation in heparinized ( $3 \mathrm{IU} / \mathrm{mL}$ ) whole human blood at $37^{\circ} \mathrm{C}$. Briefly, following blood incubation, samples were rinsed 3 times in phosphate-buffered saline (PBS) and fixed in 3\% glutaraldehyde in PBS for $30 \mathrm{~min}$, followed by $2 \%$ osmium tetroxide in PBS for $20 \mathrm{~min}$, both at room temperature (RT). Samples were subsequently dehydrated in a graded series of ethanol (from 30\% to $96 \%$ ). Out of absolute ethanol the samples were dried over the critical point of $\mathrm{CO}_{2}$ (Tc $5318 \mathrm{C}$, Pc 573,8 bar) using a critical-point dryer (CPD 030 Critical Point Dryer, Bal-Tec AG, Balzers, Liechtenstein). The samples were sputtercoated with $7 \mathrm{~nm}$ platinum and the images were recorded with a Zeiss (Oberkochen, Germany) SUPRA 50 VP at 5 $\mathrm{kV}$ using secondary electron signals and at $20 \mathrm{kV}$ using backscattered electron signals with a magnification between 250 and 10,000 times. For quantification, micrographs of random areas of each sample at 520 times magnification were taken with secondary electron signals for cell count, and with 250 times magnification of backscattered electron 
A
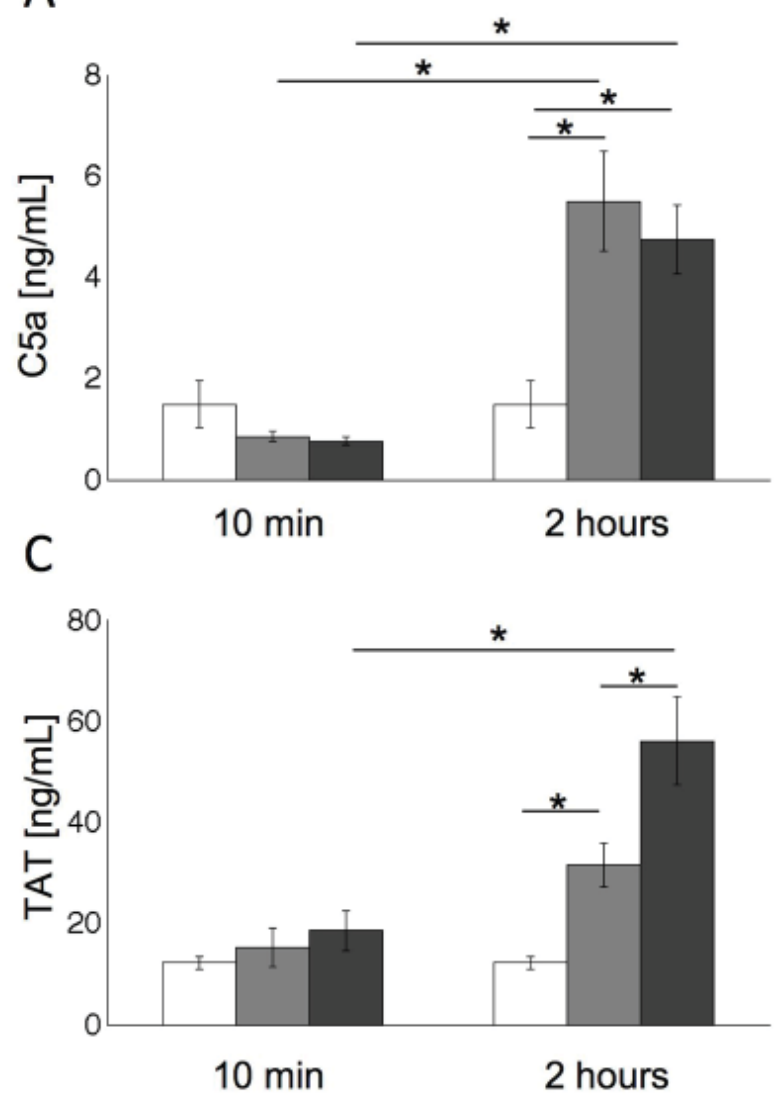

B
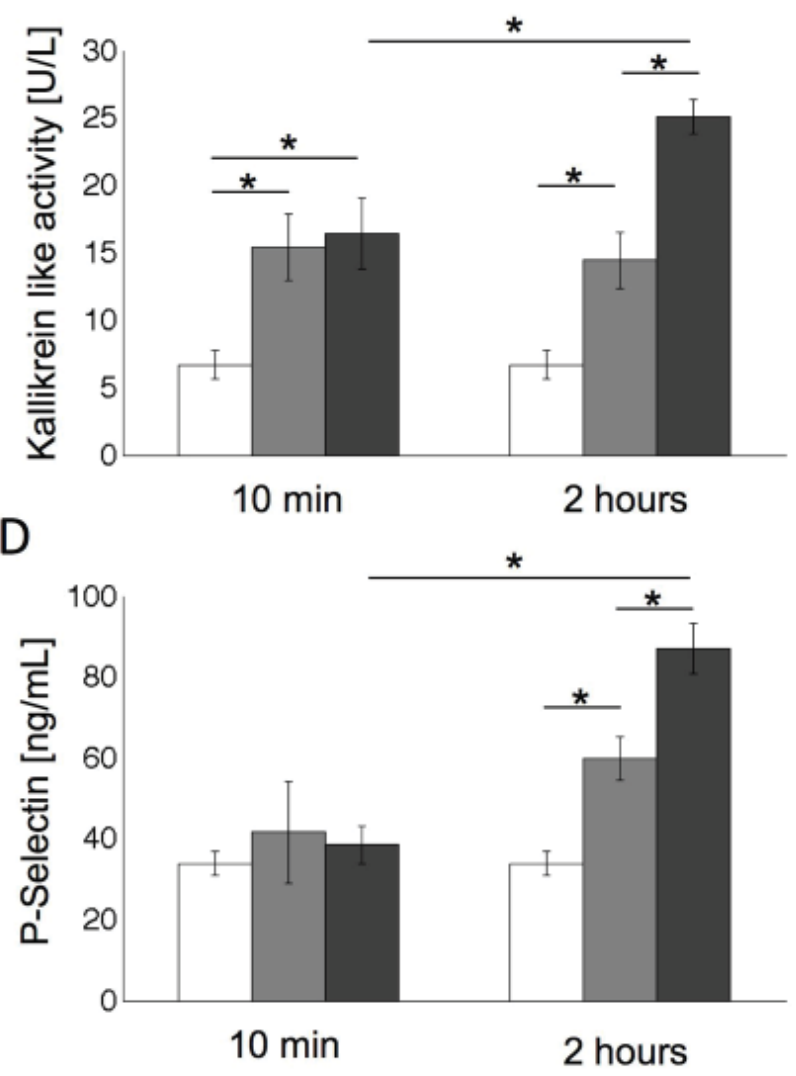

untreated alkali-treated

Fig. 1. Increase in C5a concentrations (A), Kallikrein-like activity (B), concentrations in Thrombin-antithrombin (TAT) complexes (C) and increase in sP-Selectin concentrations (D) in human whole blood anti-coagulated with 3 $\mathrm{IU} / \mathrm{mL}$ heparin before and after $10 \mathrm{~min}$ and $2 \mathrm{~h}$ of contact with untreated and alkali-treated SBA Ti surfaces at 37 ${ }^{\circ} \mathrm{C}$. Reported values correspond to mean values \pm standard error of the mean from at least 5 experiments carried out in duplicates. Statistical significance was accepted for $P<0.05$ after comparing the mean values by Bonferroni test and was designated by an asterisk.

signals for surface coverage analysis. Backscattered SEM images were obtained at constant brightness and contrast settings to minimize sample-to-sample variation. Images were analyzed with ImageJ (NIH, Bethesda, MD, USA) using a constant manually set threshold to include organic material on the surfaces followed by detection of particles with a minimum area of $100 \mu \mathrm{m}^{2}$. Experiments were performed in duplicates and five images per sample were used for quantification.

\section{Confocal laser scanning microscopy (CLSM)}

For confocal laser scanning microscopy of deposited blood components, blood-exposed alkali- and untreated SBA Ti surfaces were rinsed 3 times in PBS and subsequently fixed for $20 \mathrm{~min}$ in an aqueous solution of $4 \%(\mathrm{w} / \mathrm{v})$ PFA, $65 \mathrm{mM}$ PIPES, $25 \mathrm{mM}$ HEPES, $10 \mathrm{mM}$ EGTA and $3 \mathrm{mM}$ $\mathrm{MgCl}_{2}$ and subsequently incubated for $10 \mathrm{~min}$ in PBS containing $0.1 \%$ Triton $\mathrm{X} 100(500 \mu \mathrm{L}$ per well) for cell permeabilization. On all samples, cell nuclei were stained with 1:2000 Hoechst 33342 (Molecular Probes, Eugene, OR, USA) in PBS (Sigma-Aldrich, St. Louis, MO, USA) containing $1 \%(\mathrm{w} / \mathrm{w})$ of BSA (Bovine Serum Albumin,
SAFC, Sigma-Aldrich) for $10 \mathrm{~min}$ at RT. Staining of the actin cytoskeleton was achieved by incubating the samples in a solution of Alexa Fluor ${ }^{\circledR}$ 488-phalloidin (1:200, Molecular Probes) in $1 \%(\mathrm{w} / \mathrm{w})$ of BSA in PBS for $2 \mathrm{~h}$ at RT.

Stainings for CD41, sP-selectin and fibrin were carried out by incubating the samples in solutions of monoclonal anti-integrin $\alpha 2 b-C D 41$ (Sigma-Aldrich, No I9660), purified anti-human CD62P - P-selectin (Biolegend, San Diego, CA, USA; No 304902) or monoclonal anti-human fibrin(ogen) (Sigma-Aldrich, F9902), respectively, using 1:50 dilutions for $2 \mathrm{~h}$ followed by incubation in a solution of anti-mouse Alexa 633 (1:200, Molecular Probes) for $1 \mathrm{~h}$ at RT. CD14 staining was carried out by incubating in a solution of biotinylated anti-human CD14 antibody (1:50, R\&D Systems, No BAF183) for $30 \mathrm{~min}$ followed by streptavidin Alexa 488 (1:200, Molecular Probes) for 1 $\mathrm{h}$ at RT. All samples were washed 3 times with PBS after incubation with antibody solutions. All antibodies were diluted in $1 \%(\mathrm{w} / \mathrm{w})$ BSA in PBS. Samples were mounted on glass coverslips (24 x $50 \mathrm{~mm}$, Carl Roth) using Mowiol 4-88 mounting medium (Calbiochem; EMD Chemicals, 
A

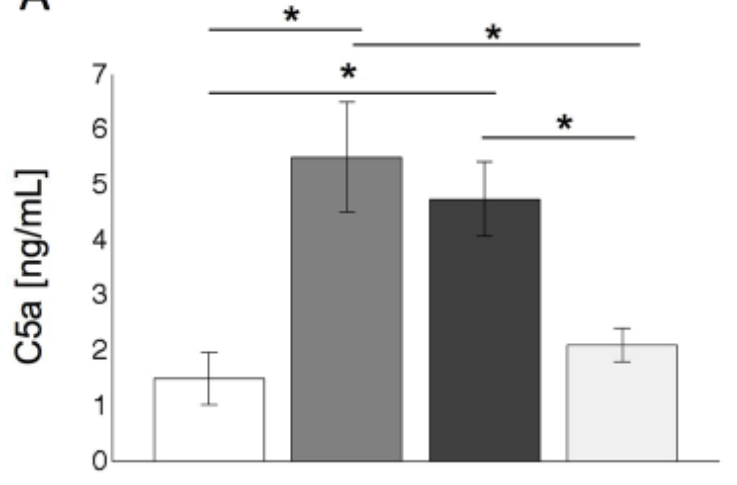

C

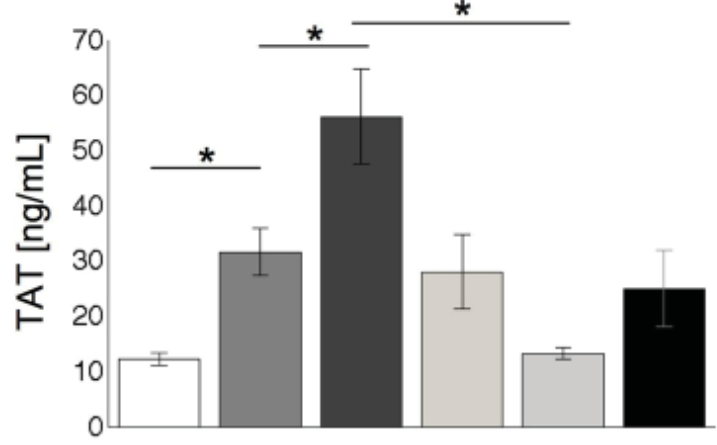

B

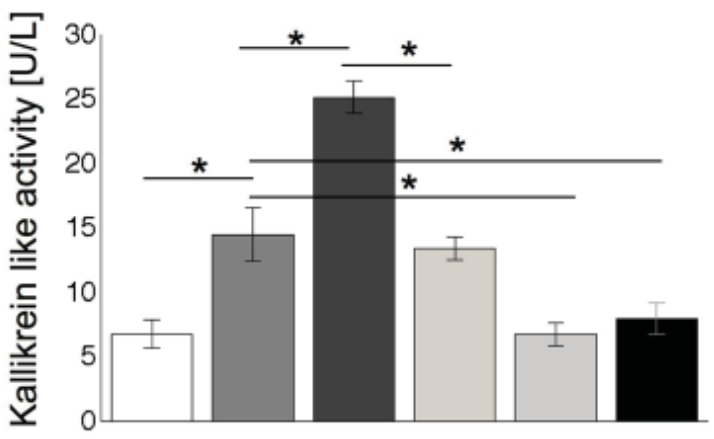

D

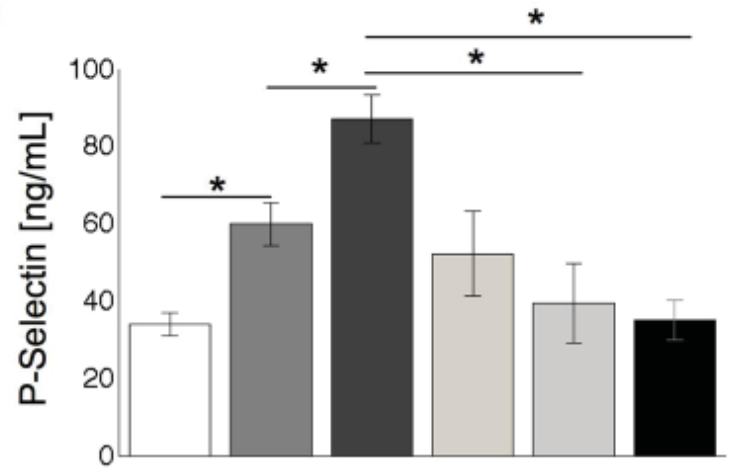
before incubation untreated stainless steel teflon glass

Fig. 2. Increase in C5a (A), Kallikrein-like activity (B), TAT complexes (C) and soluble P-Selectin (D) concentrations in partially heparinized whole human blood before and after $2 \mathrm{~h}$ contact in contact with untreated and alkali-treated SBA Ti substrates at $37^{\circ} \mathrm{C}$ and with different reference substrates. The values represent mean \pm SEM from at least 5 experiments carried out in duplicates.

Gibbstown, NJ, USA), left overnight and analyzed by laser scanning confocal microscopy (SP5, Leica Microsystems, Wetzlar, Germany). Fluorescence was analyzed using the following wavelengths: Hoechst 33342 (ex $=350 \mathrm{~nm}$ and $\mathrm{em}=440 \mathrm{~nm})$, Alexa-488 $(\mathrm{ex}=495 \mathrm{~nm}$ and $\mathrm{em}=519 \mathrm{~nm})$ and Alexa-633 $(\mathrm{ex}=632 \mathrm{~nm}$ and $\mathrm{em}=647 \mathrm{~nm})$.

\section{Statistical analysis}

All mean values were compared by one-way ANOVA analysis using Matlab 7.9 (the MathWorks Inc, USA). Statistical significance was accepted for $P<0.05$ after comparing the mean values by Bonferroni test and was designated by an asterisk.

\section{Results}

\section{Activation of the complement system, platelets and the blood coagulation cascade}

The influence of alkali treatment of sandblasted and thermal acid etched (SBA) Ti surfaces on contact activation by whole human blood was tested. Specifically, the extent of activation of the common pathway of blood coagulation, of platelet activation and of the complement system were monitored by ELISA against specific marker proteins; namely thrombin-antithrombin III (TAT) complexes, soluble P-selectin (sP-selectin) and the anaphylatoxin $\mathrm{C} 5 \mathrm{a}$, respectively. Additionally, contact activation of the intrinsic coagulation cascade as induced by direct contact with materials surfaces was assessed by the increase in kallikrein-like activity. In all cases, protein concentrations in partially-heparinized whole human blood before and after $10 \mathrm{~min}$ and $2 \mathrm{~h}$ incubation with untreated and alkalitreated SBA Ti surfaces were compared.

Fig. 1A demonstrates the increase of $\mathrm{C} 5 \mathrm{a}$ in blood upon contact with untreated and alkali- treated SBA Ti surfaces. Alkali-treatment did not significantly affect complement activation as alkali-treated and untreated SBA surfaces induced a comparable increase in $\mathrm{C} 5 \mathrm{a}$ concentrations. Both types of surfaces showed strong increase in C5a concentrations with time. $5 \mathrm{ng} / \mathrm{mL} \mathrm{C5a}$ were found after $2 \mathrm{~h}$ of incubation whereas only 1.5 and $1 \mathrm{ng} / \mathrm{mL} \mathrm{C5a}$ were detected before and after $10 \mathrm{~min}$ of incubation, respectively. C5a concentrations found after exposure to control stainless steel surfaces were comparable to the starting values before blood exposure indicating that the contributions of chamber walls and handling on the C5a levels were negligible (Fig. 2A).

The influence of alkali treatment of SBA Ti surfaces on the activation of the intrinsic cascade and the common pathway of blood coagulation were assessed by measuring kallikrein-like activity (Fig. 1C) and increase in TAT 

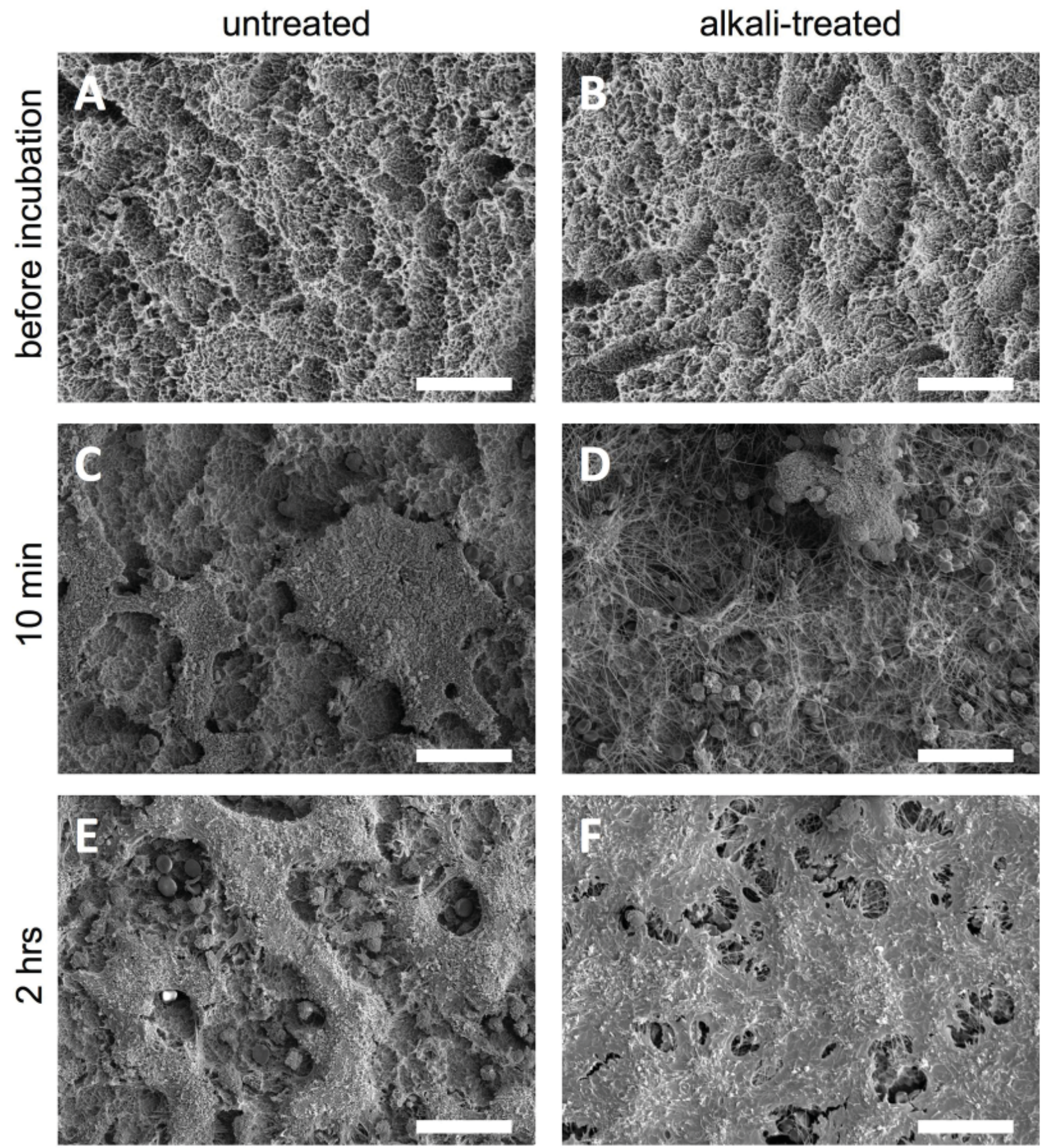

Fig. 3. Secondary electron micrographs of untreated (A, C and $\mathbf{E})$ and alkali-treated (B, D and $\mathbf{E})$ SBA Ti substrates before and after incubation in whole human blood for $10 \mathrm{~min}(\mathbf{C}$ and $\mathbf{D})$ and for $2 \mathrm{~h}(\mathbf{E}$ and $\mathbf{F})$ at $37^{\circ} \mathrm{C} . \mathrm{Bar}=20 \mu \mathrm{m}$.

complex concentrations (Fig. 1D) respectively. For increase in TAT complex concentrations as well as for kallikreinlike activity a strong increase was observed after $2 \mathrm{~h}$ as compared to $10 \mathrm{~min}$ exposure to partially heparinized blood suggesting that contact activation is clearly time dependent. Moreover, after $2 \mathrm{~h}$ of incubation with alkali-treated surfaces both kallikrein-like activity and TAT complex concentrations were significantly elevated compared to the corresponding values obtained with untreated SBA Ti surfaces. The values for kallikrein-like activity increased from $15 \mathrm{U} / \mathrm{L}$ to $25 \mathrm{U} / \mathrm{L}$ and the concentrations from TAT complexes from 30 to $55 \mathrm{ng} / \mathrm{mL}$, respectively.

The influence of alkali treatment of SBA Ti surfaces on platelet activation was assessed by comparing concentrations of sP-selectin in partially heparinized blood after contact with untreated and alkali-treated SBA Ti surfaces and is shown in Fig. 1D. The increase in SPselectin formation by alkali treatment correlated well with the corresponding increase in TAT complex formation shown in Fig. 1D. sP-selectin was only significantly increased in blood incubated for $2 \mathrm{~h}$ with untreated and alkali-treated SBA Ti surfaces (Fig. 1E). Again, no significant increase in $\mathrm{sP}$-selectin was observed after 10 min of incubation suggesting that increase in sP-selectin requires a certain surface contact time. Assessment of the C5a, TAT, kallikrein and sP-Selectin concentrations after $2 \mathrm{~h}$ after blood contact to reference Teflon surfaces evidenced that chamber walls and sample handling did 

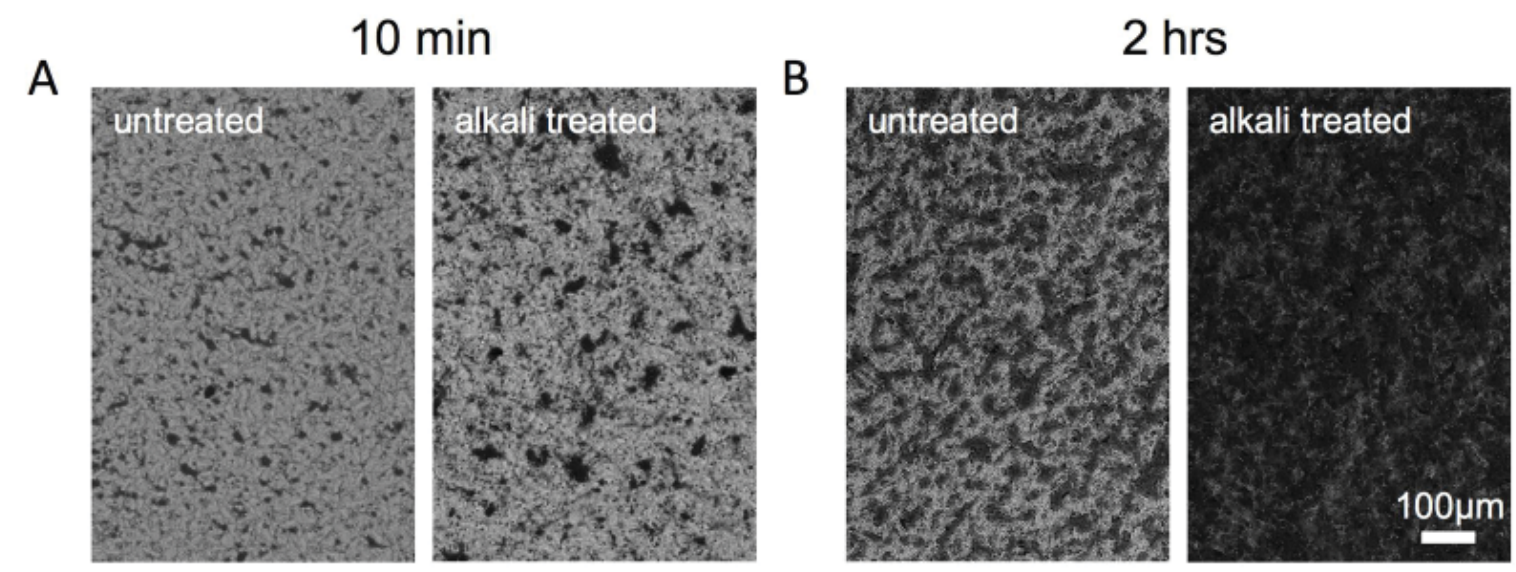

C

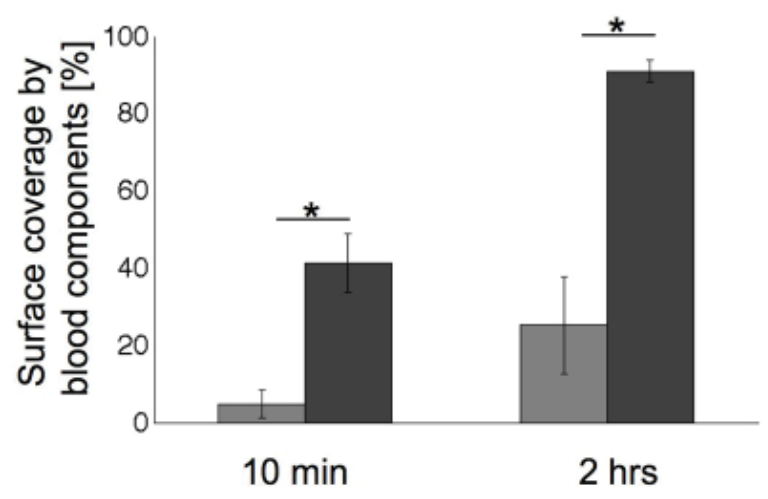

D

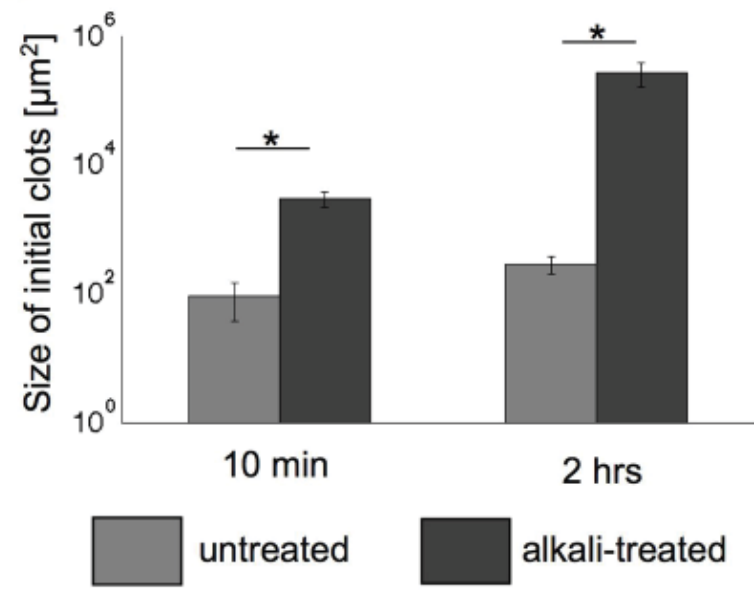

Fig. 4. Backscattered electron micrographs obtained after $10 \mathrm{~min}(\mathbf{A})$ and $2 \mathrm{~h}(\mathbf{B})$ of incubation in partially heparinized whole human blood at $37{ }^{\circ} \mathrm{C}$ on untreated and alkali- treated SBA Ti surfaces. From these images mean surface coverage by blood components (C) and mean sizes of deposited initial blood cots (D) are demonstrated. Reported values correspond to mean values \pm standard deviation from 3 experiments carried out in duplicates.

not significantly affect activation of the analyzed marker protein (Fig. 2).

\section{Morphological characterization of blood clot formation by SEM}

The influence of increased activation of the coagulation cascade by alkali-treatment was visualized by secondary electron images of the deposition of blood components on alkali-treated and untreated SBA Ti surfaces after $10 \mathrm{~min}$ and $2 \mathrm{~h}$ of incubation in low heparinized whole human blood (Fig. 3). As controls non-blood exposed SBA Ti surfaces were used (Figs. 3A,B). The images revealed clear morphological differences between the deposits formed on untreated and alkali-treated SBA Ti surfaces after 10 min (Figs. 3C,D) or $2 \mathrm{~h}$ (Figs. 3E,F) of blood exposure. After 10 min clusters of blood components were found on both surface types. In contrast to untreated surfaces alkali-treated SBA Ti surfaces were decorated additionally with a significant amount of fibrous structures. After $2 \mathrm{~h}$ of incubation, untreated surfaces were covered by a porous and incomplete layer of blood deposits, while a compact layer of deposits was observed on alkali-treated surfaces.

Fig. 4 compares backscattered SEM images that were used to determine the overall coverage with blood components and the mean size of initial clots on untreated and alkali-treated SBA Ti surfaces. Deposited blood components appear as dark regions in the backscattered electron micrograph (Fig. 4A,B). The mean surface coverage by blood components is shown in Fig. $4 \mathrm{C}$ after $10 \mathrm{~min}$ and $2 \mathrm{~h}$, respectively. It was significantly elevated on alkali-treated SBA Ti surfaces compared to untreated surfaces. The quantification of the mean size of initial clots as demonstrated in Fig. 4D furthermore supported that on alkali-treated SBA Ti surfaces significantly more blood components and cells attached. For both surfaces a strong increase of surface coverage as well as an increase in deposited initial clots was found with increased exposure time. Therefore all further experiments were analyzed after $2 \mathrm{~h}$ of blood exposure to the different SBA Ti surfaces.

\section{Morphologic characterization of blood clot composition, structure and platelet as well as macrophage activation on SBA Ti surfaces}

In order to analyze the differences between the blood clots formed on SBA Ti surfaces with and without alkali treatment the composition and structure of the clots formed after $2 \mathrm{~h}$ of incubation were characterized by confocal laser scanning microscopy after staining with specific antibodies. Also activation of platelets and macrophages attached to the surfaces were analyzed. 

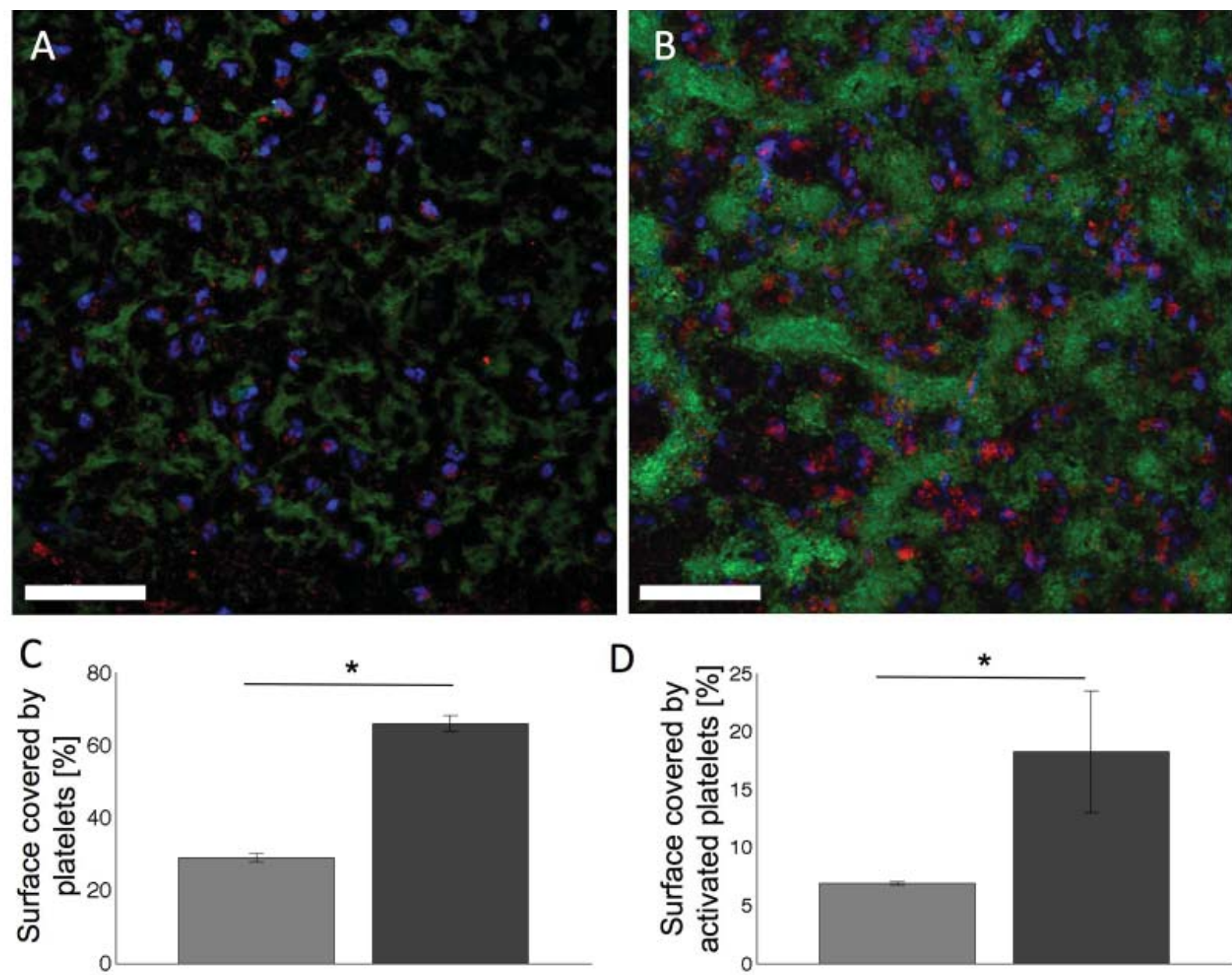

D

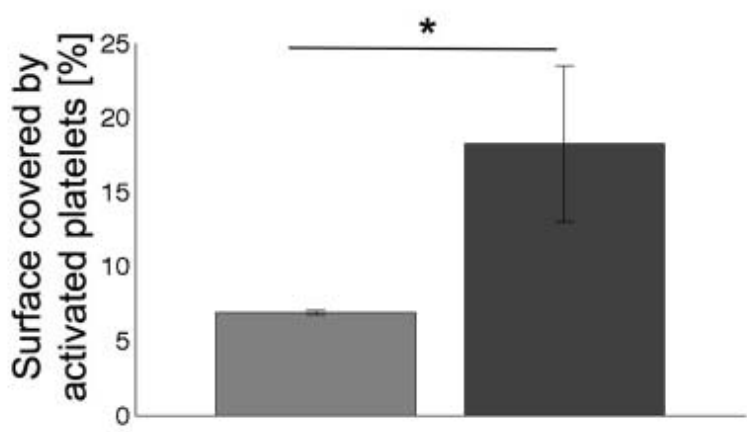

untreated

alkali-treated

Fig. 5. Immunoflurescence micrographs of untreated (A) and alkali-treated (B) SBA Ti surfaces after exposure to partially heparinized whole human blood for $2 \mathrm{~h}$ at $37^{\circ} \mathrm{C}$. Surfaces were stained with Hoechst (blue) for nuclei, with phalloidin-Alexa 488 conjugate (green) for actin and with anti-CD62p (red) for activated platelets. (C) Represents a quantification of surface coverage by blood cells as determined after staining the actin cytoskeleton. (D) Represents surface coverage of CD62p-positive-activated platelets. Reported values in (C) and (D) correspond to mean values \pm standard deviations from at least 3 experiments carried out in duplicates. Bar $=50 \mu \mathrm{m}$.

Platelet content and activation in the blood clots were analyzed by (immuno-)stainings of a platelet surface marker CD62p, the actin cytoskeleton and cell nuclei on untreated and on alkali-treated SBA Ti surfaces. The total number of cells was determined by nuclear staining while the antibody against CD62p was used to stain persistently activated platelets. Figs. 5A and 5B show projections of Z-stacks obtained by confocal laser scanning microscopy (CLSM) images of blood clots formed on untreated and alkali-treated SBA Ti surfaces, respectively. Fig. 5C shows surface coverage by the total number of cells and Fig. 5D by activated CD62p-positive platelets. Both, the overall coverage with nucleated cells and with CD62p-positive platelets were significantly increased on alkali-treated surfaces (66\% and 18\%) compared to the corresponding values on untreated SBA Ti surfaces (29\% and 7\%). However the ratio of CD62p-positive platelets to total nucleated cells was found to be about $25 \%$ for both surfaces types, suggesting that the percentage of activated platelets did not change by alkali treatment of the surfaces however the absolute number of platelets adhered was significantly increased by 44 and $38 \%$, respectively.

Leukocytes represent the most abundant group of nucleated cells in blood are key mediators of blood coagulation, inflammation and wound healing. One of these cell types are monocytes/macrophages that were detected on fluorescence micrographs after staining against nuclei to determine the total cell number of nucleated cells and by a monocyte /macrophage specific surface marker CD14 on untreated and alkali-treated SBA Ti surfaces. As seen in Figs. 6A-D the total number of cells was significantly increased on alkali-treated SBA Ti surfaces compared to untreated surfaces and this increase was paralleled with a significant change in cell types adhered. Figs. $6 \mathrm{C}, \mathrm{D}$ demonstrate that the mean number of monocytes/ macrophages were similar on both surfaces (about 600 cells $/ \mathrm{mm}^{2}$ ), while the mean number of leukocytes was significantly increased on alkali-treated surfaces $(2,200$ 

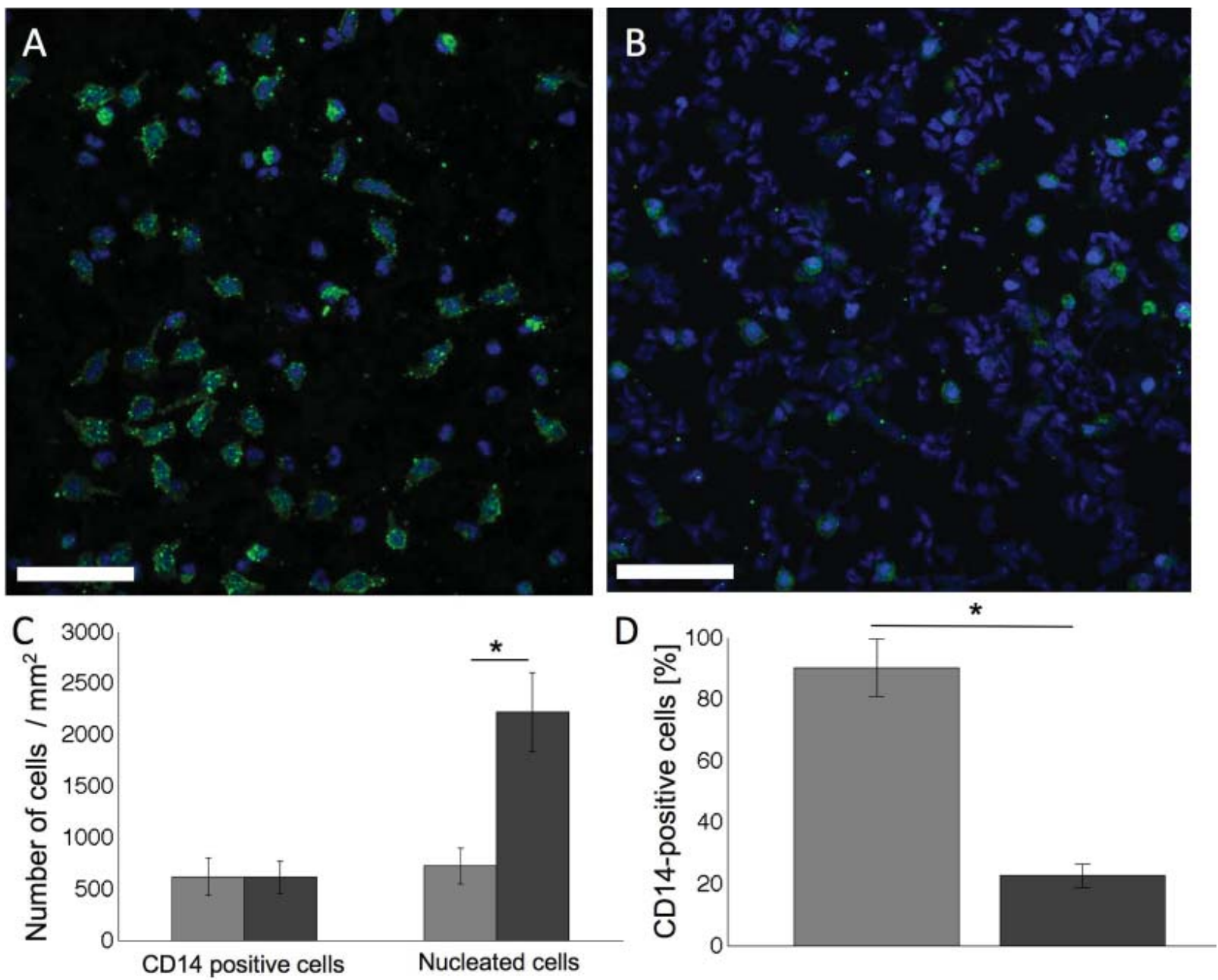

\section{untreated}

alkali-treated

Fig. 6. Immunofluorescence micrographs of untreated and alkali-treated SBA Ti surfaces after $2 \mathrm{~h}$ of incubation in partially heparinized whole human blood stained with Hoechst (blue) for nuclei and with CD14 (green) for monocytes/ macrophages. The number of adhered nucleated cells is shown in (C) and the ratio between CD14-positive cells to the total number of cells is displayed in (D). Reported values correspond to mean values \pm standard deviation from at least 3 experiments carried out in duplicates. Bar $=50 \mu \mathrm{m}$.

cells $/ \mathrm{mm}^{2}$ ) compared to the untreated surfaces $(750$ cells/ $\mathrm{mm}^{2}$ ), resulting in a relative monocyte/macrophage content of $22 \%$ on alkali treated SBA Ti surfaces compared to a corresponding value of $90 \%$ on the untreated surfaces.

Crosslinked fibrin(ogen) forms the first provisional matrix after an injury and the structure and amount of deposited fibrin significantly affects subsequent wound healing thus also implant integration (Laurens et al., 2006). Therefore fibrin deposition was compared on untreated and alkali-treated SBA Ti surfaces after $2 \mathrm{~h}$ of incubation in partially heparinized whole human blood. Fibrin deposits were stained with an anti-fibrin(ogen) antibody. As evidenced by the fluorescence micrographs in Fig. 7A clear difference in the amount and structure of fibrin fibers were found between alkali-treated and untreated SBA Ti surfaces. The clots formed on untreated SBA Ti surfaces contained unstructured and discontinuous fibrin(ogen) aggregates while a dense mesh of fibrin fibers was detected on alkali-treated surfaces.
Finally, the organization of deposited cellular components within the fibrin fiber network, as well as the overall thickness of the deposited blood clots, were compared. The surfaces were incubated in whole human blood for $2 \mathrm{~h}$ and subsequently stained for nucleated cells, for platelets, and for fibrin fibers as displayed in (Fig. 8A). Images of the deposited clots obtained at 0 and $15 \mu \mathrm{m}$ above untreated SBA Ti surfaces and at 0,15 and $30 \mu \mathrm{m}$ above alkali-treated substrates are shown in Figs. 8A, a and $\mathrm{b}$ and in Figs. 8A, d, e, and f, respectively. The comparison of fluorescence micrographs obtained at 0 and $15 \mu \mathrm{m}$ above an untreated SBA Ti surface demonstrated that the blood clot structure did not significantly differ through the thickness of the blood clot. Whereas for the clot found on alkali-treated surfaces the composition changed with the distance from the actual Ti surface in that close to the surface cell nuclei are found $(0 \mu \mathrm{m})$, whereas in 15 and 30 $\mu \mathrm{m}$ above the surface actin-stained structures without cell nuclei (platelets) and increasing amounts of fibrin fibers 

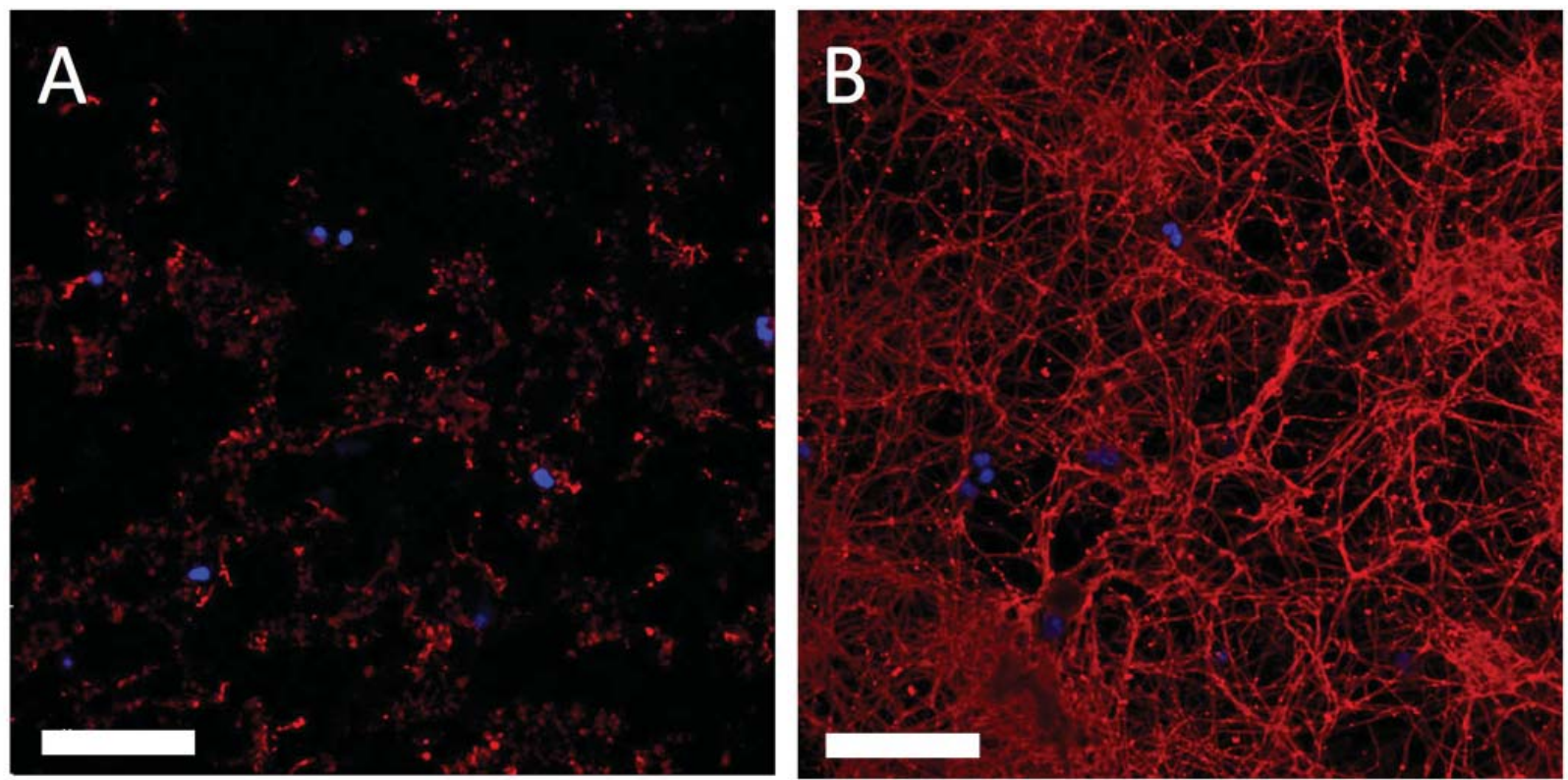

Fig. 7. Immunofluorescence micrographs of untreated (A) and alkali-treated (B) SBA Ti surfaces after $2 \mathrm{~h}$ of incubation in partially heparinized human whole blood at $37^{\circ} \mathrm{C}$ stained for fibrin (red) and with Hoechst (blue) for nuclei. Bar $=50 \mu \mathrm{m}$

\begin{abstract}
Animation 1 (available from the eCM Journal paper website). $z$-stacks of confocal laser scanning micrographs of untreated (A) and alkali-treated (B) SBA Ti surfaces after $2 \mathrm{~h}$ of incubation in partially heparinized human whole blood at $37{ }^{\circ} \mathrm{C}$. Samples were stained with Hoechst (blue) for nuclei, with phalloidin-Alexa 488 conjugate (green) for actin and with anti-fibrin-(red) for fibrin fibers. The z-stacks start at the surface $(0 \mu \mathrm{m})$ and every $150 \mathrm{~nm}$ an image was acquired until the entire thickness of the blood clots was imaged.
\end{abstract}

are detectable. The thickness of the deposited blood clot on untreated and alkali-treated SBA Ti surfaces was estimated by determining the thickness of Z-stacks obtained by CLSM (Fig. 7A, c). The thickness of the blood clot deposited on alkali-treated SBA Ti surfaces was strongly increased $(\sim 35$ $\mu \mathrm{m})$ as compared to untreated surfaces $(\sim 20 \mu \mathrm{m})$. Fig. $8 \mathrm{~B}$ visualizes the organization of the blood clots on alkalitreated (Figs. 8B b and d) and untreated (Figs. 8B a and c) surfaces by $3 \mathrm{D}$-reconstructions and optical cross sections. The $3 \mathrm{D}$ reconstruction as well as the vertical cross section of the blood clot further indicate an overall discontinuous appearance of the clot and regular lateral distribution of platelets, fibrin patches and nucleated cells on the untreated SBA Ti surface. In contrast the composition of blood clots after $2 \mathrm{~h}$ of incubation on alkali-treated substrates showed a layered architecture. Figs. 8A d, e and $\mathrm{f}$ demonstrate the presence of high numbers of nucleated cells but only few platelet aggregates (actin-stained structures without nuclei) directly on the surface. Fibrin fibers seem to be interwoven with platelet patches (large areas of actin-stained structures without nuclei) between $15 \mu \mathrm{m}$ and $30 \mu \mathrm{m}$ distance from the surface. The $3 \mathrm{D}$ reconstructions and optical cross sections in Figs. 8B b and d confirmed these findings. Entire scans through z-stacks on untreated and alkali-treated SBA Ti surfaces visualize the composition and organization of the blood clots and furthermore indicate a strong association of platelets and leukocytes with fibrin fibers predominantly in the blood-facing regions of the clots providing a very dense and continuous interface between the materials surface and the blood flow (Animation 1A and $1 \mathrm{~B}$, available from the eCM Journal paper website).

\section{Discussion}

The strong correlation between impaired blood coagulation followed by impaired wound healing underlines the importance of blood coagulation for wound healing, later followed by implant integration (Xu et al., 2010). The aim of this contribution was to correlate increased osseointegrative potential of alkali-treated SBA Ti implants that was demonstrated for the early healing phase of dental implants (Calvo-Guirado et al., 2010; Stadlinger et al., 2009) with exposure of blood to differentially-treated titanium surfaces. Initiation of blood coagulation, platelet and complement activation as well as the architecture of the resulting blood clots on alkali-treated and untreated SBA Ti surfaces was analyzed in vitro. In order to do so alkali-treated and untreated SBA Ti surfaces were exposed for different times to partially heparinized blood. Kallikrein-like activity as well as concentrations of TAT complexes and sP-selectin were significantly increased with increasing exposure time to human whole blood on alkali-treated surfaces. These findings might suggest that alkali-treatment of SBA Ti surfaces increased the activation of the common pathways of blood coagulation and of platelet activation via contact activation. In contrast, the increase in $\mathrm{C} 5 \mathrm{a}$ concentrations and hence the activation of the complement system was comparable 
A
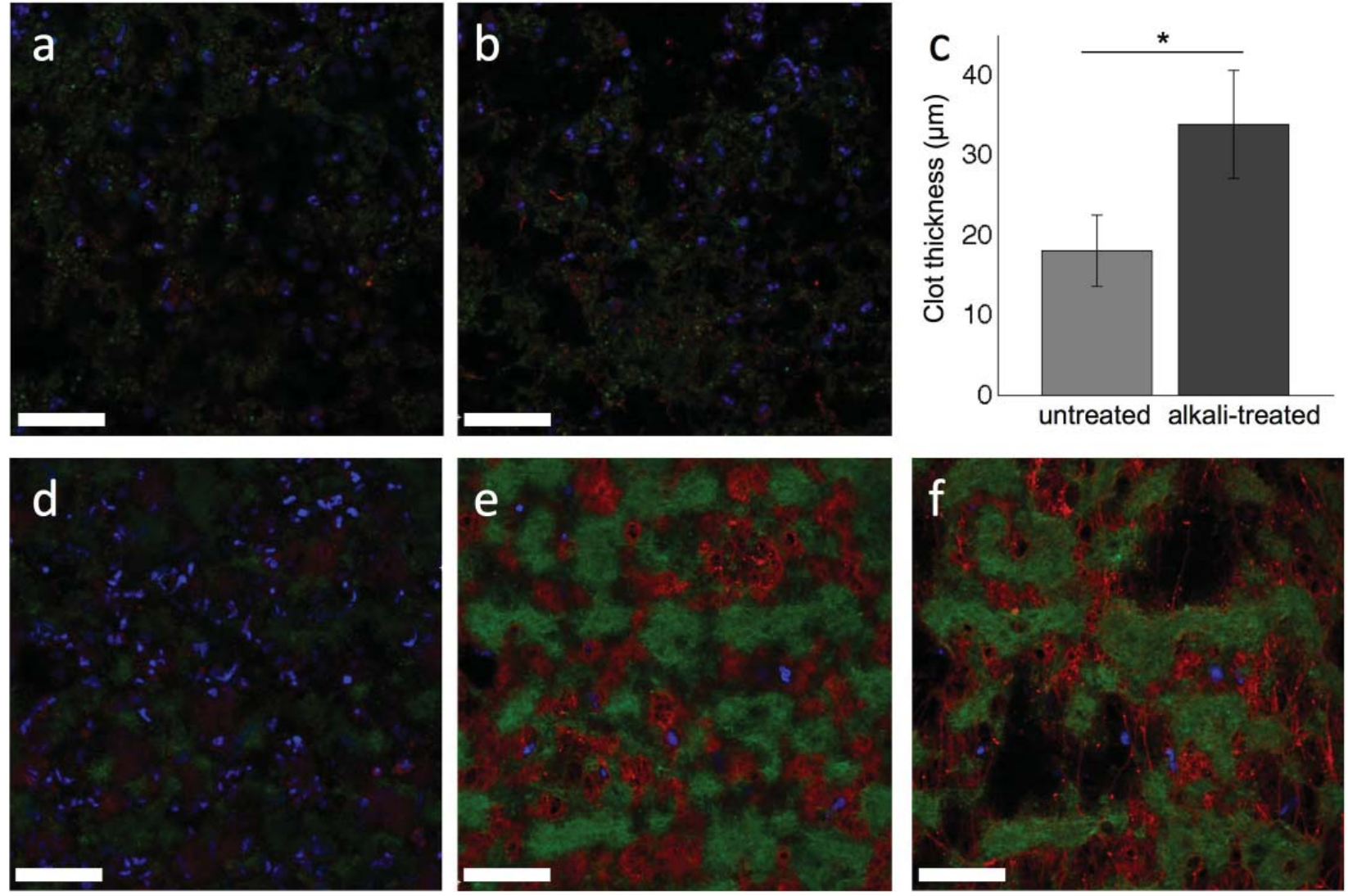

B
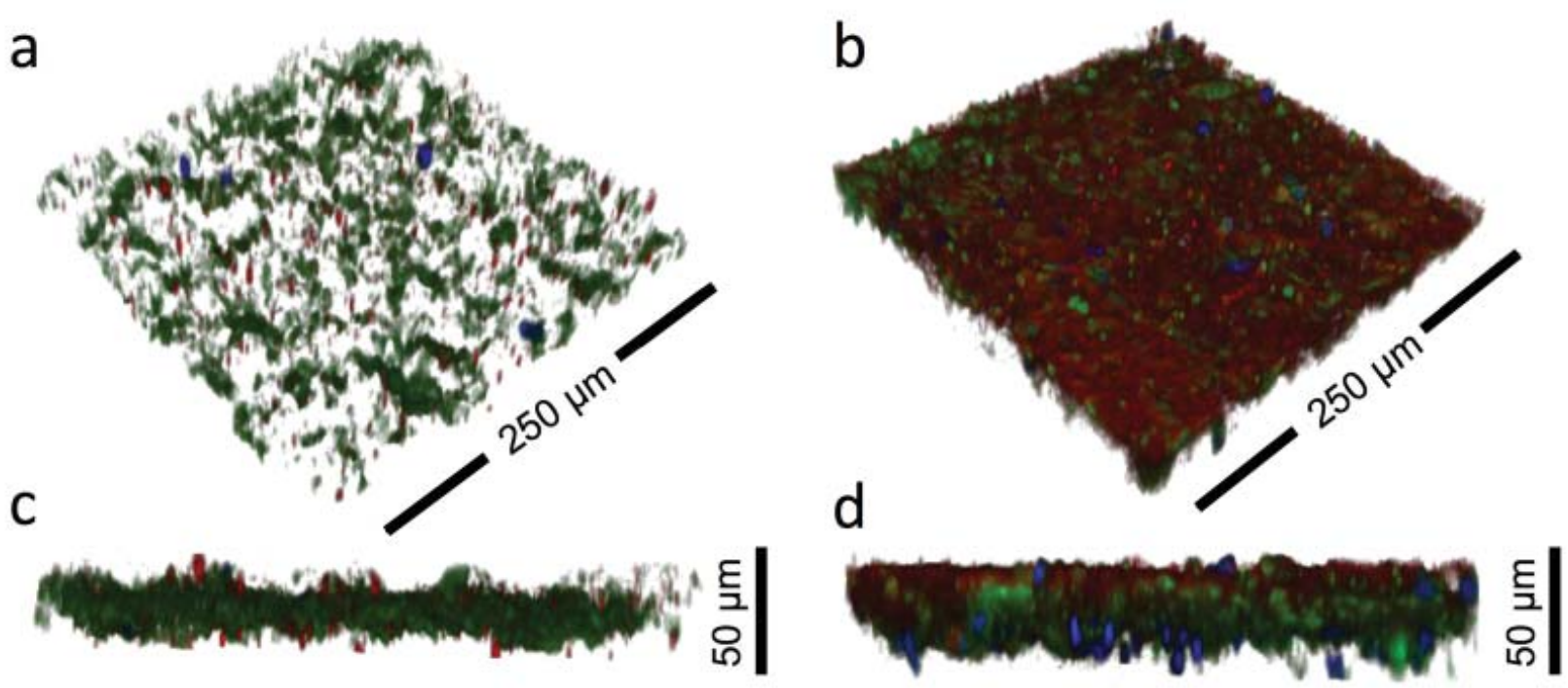

Fig. 8. (A) Confocal laser scanning microscope images obtained from blood clots formed after $2 \mathrm{~h}$ of incubation in partially heparinized human whole blood at $37^{\circ} \mathrm{C}$ on untreated (a and b) and alkali-treated (d, e, f) SBA Ti surfaces. Samples were stained with Hoechst (blue) for nuclei, with phalloidin-Alexa 488 conjugate (green) for actin and with anti-fibrin (red) for fibrin. Images a and $\mathbf{d}$ correspond to images obtained at the surface $(0 \mu \mathrm{m}), \mathbf{b}$ and $\mathbf{e}$ at $15 \mu \mathrm{m}$ and $\mathbf{f}$ at $30 \mu \mathrm{m}$ above the material surface. Graph $\mathbf{c}$ reports the mean blood clot thickness \pm standard deviations on untreated and alkali-treated SBA Ti surfaces after $2 \mathrm{~h}$ of incubation in whole human blood at $37^{\circ} \mathrm{C}$ as determined from entire z-stacks of CLSM images. Bars $=50 \mu \mathrm{m}$. (B) $3 \mathrm{D}$ reconstructions (a and $\mathbf{b}$ ) and cross sections (c and d) obtained from CLSM z-stacks of the blood clot formed on untreated (a and c) and alkali-treated (b and d) SBA Ti surfaces stained for the actin cytoskeleton. (green), fibrin (red) and cell nuclei (blue). a and $\mathbf{b}$ represent regions of $250 \mu \mathrm{m} \times 250 \mu \mathrm{m}$ The bars in $\mathbf{c}$ and $\mathbf{d}$ represent $50 \mu \mathrm{m}$. 

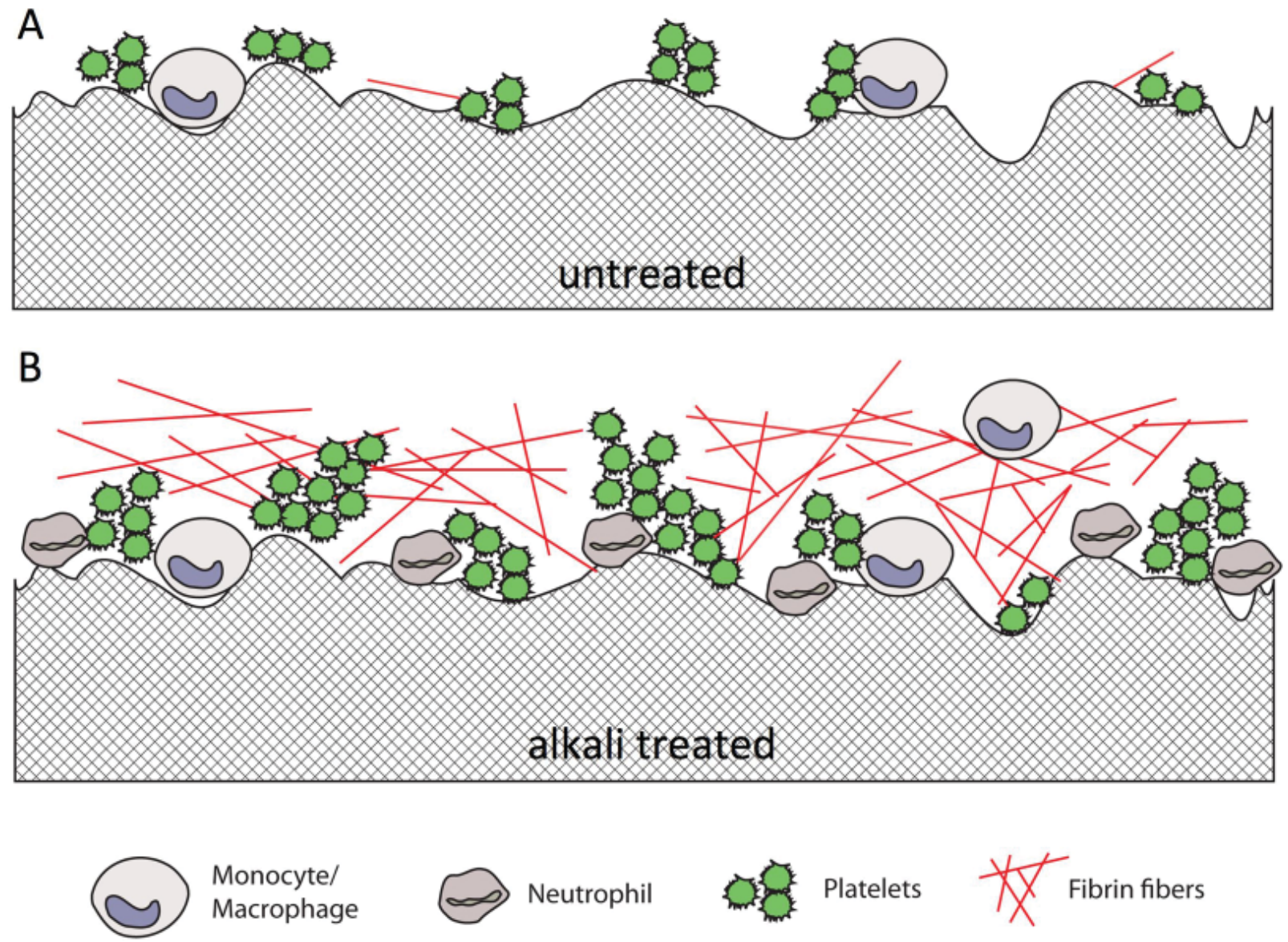

Neutrophil
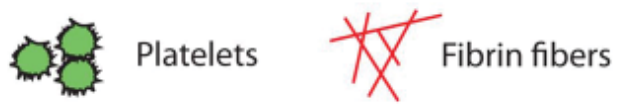

Fig. 9. Schematic of different blood clots observed on untreated (A) or alkali-treated (B) SBA Ti surfaces after $2 \mathrm{~h}$ of incubation in partially heparinized whole human blood at $37^{\circ} \mathrm{C}$.

for both surface types. Additionally a significant increase in blood clot formation was observed on alkali-treated SBA Ti surfaces affecting both the physical dimensions as well as the composition of deposited blood clots. Fig. 9 summarizes the most important differences in the blood clots formed on both surface types. Clearly organized blood clots composed of surface adhered nucleated cells being neutrophils and monocytes/macrophages followed by a layered structure of platelets entrapped within fibrin fiber networks on alkali-treated SBA Ti surfaces, while patchy blood clots lacking fibrin fibrils were observed on untreated SBA Ti surfaces. Blood clot formation and activation of blood coagulation factors were strongly time dependent on both surfaces indicating potential amplification of initial contact activation by autokrine and parakrine mechanisms. Due to their strong chemoattractant, mitogenic and proinflammatory stimulus activated platelets, leukocytes and thrombin might be considered as key players for the initiation of thrombogenesis, acute inflammation and wound healing (Werner and Grose, 2003; Zarbock et al., 2007). More specifically: activated platelets and leukocytes were reported to release and/or activate a broad range of mitogenes, chemokines and proteases acting as potent mediators of blood coagulation and inflammation like e.g. PDGF; TGF- $\beta$, VEGF or TNF- $\alpha$, IL-1 $\beta$, IL-6, IL-8, cathepsin $\mathrm{G}$ or kallikrein. Besides amplifying, maintaining or down-regulating platelet and leukocyte activation via auto- and/or parakrine mechanisms these factors activate the intrinsic and extrinsic pathways of coagulation and recruit and stimulate immune and osteogenic cells thus trigger important key processes of the downstream wound healing cascade (Del Maschio et al., 1989; Bazzoni et al., 1992; Del Maschio et al., 1993; Slater et al., 1995; Werner and Grose, 2003; Gorbet and Sefton, 2004; Kilian et al., 2004; Zarbock et al., 2007). Thrombin, e.g., plays a key role for leukocyte and platelet activation and induces the formation of a fibrin matrix, which allows cell invasion and acts as a sustained release system for secreted cytokines and mitogens (Brass, 2003; Mosesson, 2005). Additionally, direct stimulatory potential of thrombin on osteogenesis has been reported (Karp et al., 2005; Li et al., 2005; Song et al., 2005; Wang et al., 2005; Pagel et al., 2006; Ryaby et al., 2006; Pagel et al., 2009 ). This strong relation between the activation of blood coagulation, acute inflammation and osteogenesis suggests that thrombogenesis provides important stimuli for osseointegration of endosseous implants (Stanford, 2010).

Several in vitro studies have addressed the influence of topographical (Park et al., 2001; Di Iorio et al., 2005) and physicochemical surface properties (Nygren et al., 1997; Hong et al., 1999; Eriksson and Nygren, 2001; Hong et al., 2005; Arvidsson et al., 2007) of Ti surfaces 

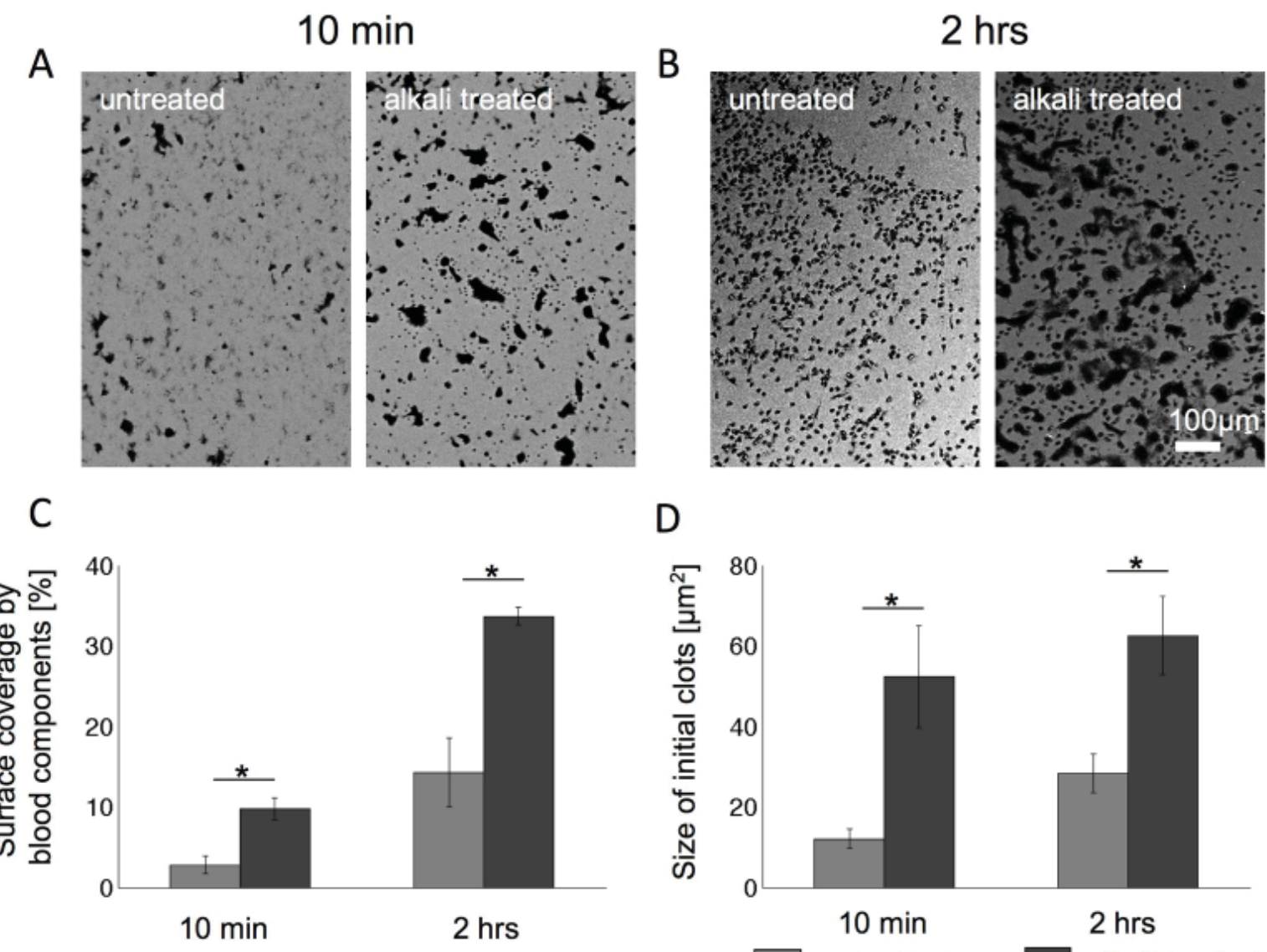

D
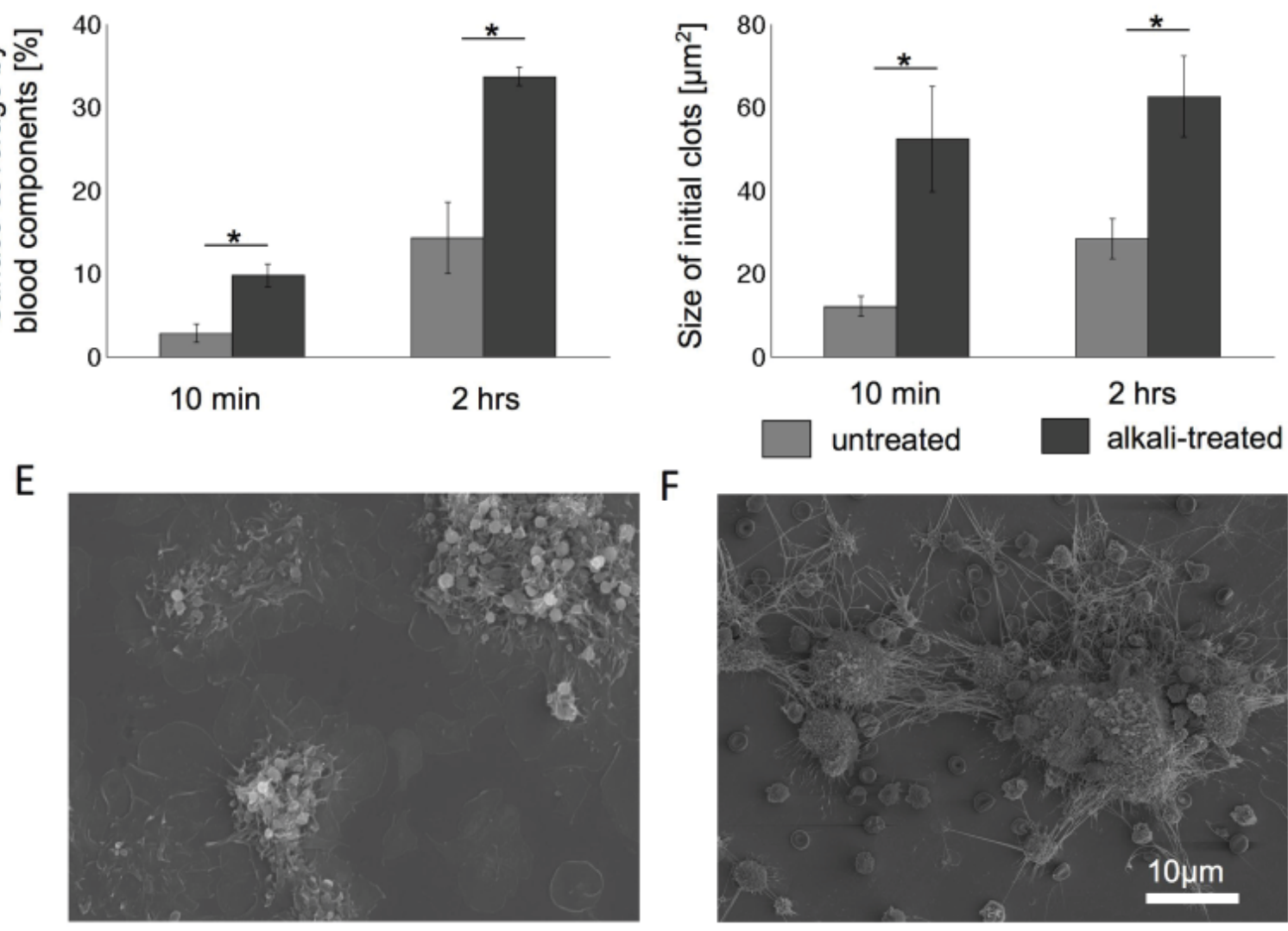

F

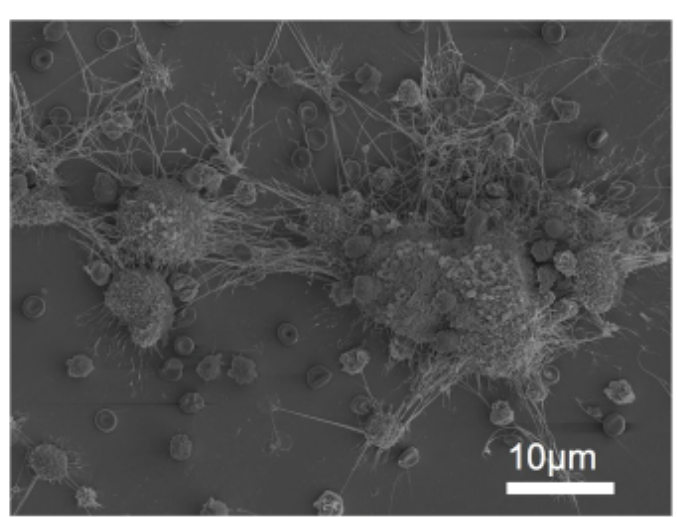

Fig. 10. Backscattered electron micrographs obtained after $10 \mathrm{~min}(\mathbf{A})$ and $2 \mathrm{~h}(\mathbf{B})$ of incubation in partially heparinized whole human blood at $37^{\circ} \mathrm{C}$ on untreated and alkali-treated polished Ti surfaces. From these images mean surface coverage by blood components (C) and mean sizes of deposited initial blood cots (D) are demonstrated. Secondary electron micrographs of untreated (E) and alkali-treated (F) polished Ti surfaces after 10 min incubation in whole human at $37^{\circ} \mathrm{C}$. Reported values in $\mathbf{C}$ and $\mathbf{D}$ correspond to mean values \pm standard deviation from 3 experiments carried out in duplicates.

on the activation of blood coagulation, the adhesion of blood cells or the adsorption of plasma proteins. These studies indicate that native $\mathrm{Ti}$ is intrinsically highly thrombogenic due to strong contact activation (Hong et al., 1998; Hong et al., 1999; Arvidsson et al., 2007). Furthermore, both topographical and physicochemical properties of the surfaces were reported to influence the activation of blood coagulation. Surface roughness, e.g., was reported to enhance platelet activation and blood clot retention (Park et al., 2001; Di Iorio et al., 2005;), while the physicochemical properties of Ti surfaces were shown to influence contact activation or the adhesion and activation of leukocytes properties (Nygren et al., 1997; Hong et al., 1999; Eriksson and Nygren, 2001; Hong et al., 2005; Arvidsson et al., 2007). However, variation of surface chemistry and topography were often coupled within these studies and experimental conditions and blood products used greatly varied between these studies, which limits their comparability.

As recently demonstrated alkali treatment of SBA Ti surfaces does not affect surface topography and hence the changes in blood coagulation in this study can be directly 
correlated to changes of the surface chemistry induced by the applied alkali treatment (Tugulu et al., 2010). The change in surface chemistry was evidenced by a decrease in contact angle from $120^{\circ}$ down to below $5^{\circ}$ after treatment with alkali. Chemical differences were detected by XPS and ToF-Sims being a decrease in hydrocarbon content after alkali treatment and mainly fragments of $\mathrm{TiO}_{2}-\mathrm{x}$, sodium hydroxide and sodium carbonate were detected (Tugulu et al., 2010). Moreover, the sum of anionic species directly at the surface was significantly increased suggesting an increased negative charge of alkali-treated SBA Ti surfaces (Tugulu et al., 2010).

The increase described here in kallikrein-like activity suggests that blood coagulation on SBA Ti surfaces was induced with increasing contact times. Even stronger kallirein-like activity was observed on alkali-treated SBA Ti. These findings are consistent with a previous report by Hong et al., who reported a significant activation of the intrinsic cascade of blood coagulation on Ti and TiN surfaces (Hong et al., 1999). Griffin has furthermore described the importance of negative surface charge for surface activation of factor XII and hence contact activation (Griffin, 1978).

The increase of C5a indicated a time dependent increase of complement activation on SBA Ti surfaces without being significantly affected by alkali treatment. Since factor XIIa, kallikrein and thrombin represent positive regulators of complement activation, C5a formation on SBA Ti surfaces might at least partly be induced by activation of blood coagulation. Moreover C5a represents one of the factors, which might induce leukocyte activation via direct binding to leukocyte surface receptors (Gorbet and Sefton, 2004). A possible mechanism for the onset of blood clot formation on SBA Ti surfaces might combine platelet activation by thrombin and platelet entrapment within fibrin fibers via fibrinogen binding integrin $\alpha \mathrm{IIb} \beta 3$ mediated bridging of activated platelets (Jackson, 2007). Both fibrin polymerization and fibrinogen release by activated platelets are stimulated by thrombin. The here observed formation of well-structured fibrin networks on alkali-treated SBA Ti surfaces and the lack of fibrin fiber formation and their deposition on untreated SBA Ti surfaces might therefore be related to the differences in thrombin activation as discussed by Wolberg (2007).

Eriksson and Nygren reported a strong influence of activation of blood coagulation on leukocyte adhesion to $\mathrm{Ti}$ surfaces, which is consistent with our findings of increased densities of nucleated cells (leukocytes - presumably neutrophils) on alkali-treated SBA Ti substrates (Eriksson and Nygren, 2001). Activated platelets and leukocytes were reported to recruit each other primarily via P-Selectin glycoprotein ligand-1 (PSGL-1) interactions (Hara et al., 2010; Nomura et al., 2000). This binding is subsequently reinforced via integrin $\alpha \mathrm{M} \beta 2$ (CD11b/CD18 or Mac-1) binding to platelet GPIb or to fibrinogen, which is bound to platelet GPIIb/IIIa or $\alpha \mathrm{V} ß 3$ integrin (Zarbock et al., 2007). Leukocytes were further reported to mediate contact activation as well as release tissue factor and kallikrein, which might contribute to the further activation and amplification of blood coagulation on SBA Ti surfaces
(Gorbet and Sefton, 2004; Henderson et al., 1994; Newball et al., 1975; Wachtfogel et al., 1983). As demonstrated by Goel et al., neutrophils enhance fibrin formation and deposition (Goel and Diamond, 2003). Thus the increased number of neutrophils might also account for the increased fibrin polymerization on alkali-treated SBA Ti surfaces.

Gorbet and Sefton have recently proposed a model of time dependent biomaterial-associated thrombogenicity with a sequential change from contact activation of the blood clotting cascade, to platelet activation and later to leukocyte mediated activation of the tissue factor pathway as the primary source of thrombin activation and thrombogeneicity (Gorbet and Sefton, 2004). The here studied clot formation and activation of blood coagulation on SBA Ti surfaces confirms this model.

Summarizing, one can say that minute changes in the surface chemistry of SBA Ti surfaces induced by alkali treatment induced profound changes in initial blood clot formation. Further studies need to determine if these morphological and compositional changes of the formed blood clot are followed by improved wound healing and osseointegration.

\section{References}

Anderson JM (2001) Biological responses to materials. Annu Rev Mat Res 31: 81-110.

Arvidsson S, Askendal A, Tengvall P (2007) Blood plasma contact activation on silicon, titanium and aluminium. Biomaterials 28: 1346-1354.

Bazzoni G, Dejana E, Del Maschio A (1992) Plateletdependent modulation of neutrophil function. Pharmacol Res 26: 269-272.

Brass LF (2003) Thrombin and platelet activation. Chest 124: 18S-25S.

Buser D, Broggini N, Wieland M, Schenk RK, Denzer AJ, Cochran DL, Hoffmann B, Lussi A, Steinemann SG (2004) Enhanced bone apposition to a chemically modified SLA titanium surface. J Dent Res 83: 529-533.

Calvo-Guirado JL, Ortiz-Ruiz AJ, Negri B, Lopez-Mari L, Rodriguez-Barba C, Schlottig F (2010) Histological and histomorphometric evaluation of immediate implant pacement on a dog model with a new implant surface treatment. Clin Oral Implants Res 21: 308-315.

Del Maschio A, Corvazier E, Maillet F, Kazatchkine MD, Maclouf J (1989) Platelet-dependent induction and amplification of polymorphonuclear leucocyte lysosomal enzyme release. Br J Haematol 72: 329-335.

Del Maschio A, Dejana E, Bazzoni G (1993) Bidirectional modulation of platelet and polymorphonuclear leukocyte activities. Ann Hematol 67: 23-31.

Di Iorio D, Traini T, Degidi M, Caputi S, Neugebauer J, Piattelli A (2005) Quantitative evaluation of the fibrin clot extension on different implant surfaces: An in vitro study. J Biomed Mater Res B Appl Biomater 74: 636-642.

Diquélou A, Lemozy S, Dupouy D, Boneu B, Sakariassen K, Cadroy Y (1994) Effect of blood flow on thrombin generation is dependent on the nature of the thrombogenic surface. Blood 84: 2206-2213. 
Eriksson C, Nygren H (2001) Polymorphonuclear leukocytes in coagulating whole blood recognize hydrophilic and hydrophobic titanium surfaces by different adhesion receptors and show different patterns of receptor expression. J Lab Clin Med 137: 296-302.

Gallimore MJ, Friberger P (1982) Simple chromogenic peptide substrate assays for determining prekallikrein, kallikrein inhibition and kallikrein "like" activity in human plasma. Thromb Res 25: 293-298.

Gardinali M, Padalino P, Vesconi S, Calcagno A, Ciappellano S, Conciato L, Chiara O, Agostoni A, Nespoli A (1992) Complement activation and polymorphonuclear neutrophil leukocyte elastase in sepsis. Correlation with severity of disease. Arch Surg 127: 1219-1224.

Goel MS, Diamond SL (2003) Neutrophil cathepsin G promotes prothrombinase and fibrin formation under flow conditions by activating fibrinogen-adherent platelets. J Biol Chem 278: 9458-9463.

Gorbet MB, Sefton MV (2004) Biomaterial-associated thrombosis: Roles of coagulation factors, complement, platelets and leukocytes. Biomaterials 25: 5681-5703.

Griffin JH (1978) Role of surface in surface-dependent activation of Hageman factor (blood coagulation Factor XII). Proc Natl Acad Sci USA 75: 1998-2002.

Griffin JH, Cochrane CG (1976) Mechanisms for the involvement of high molecular weight kininogen in surface-dependent reactions of Hageman factor. Proc Natl Acad Sci USA 73: 2554-2558.

Hara T, Shimizu K, Ogawa F, Yanaba K, Iwata Y, Muroi E, Takenaka M, Komura K, Hasegawa M, Fujimoto M, Sato S (2010) Platelets control leukocyte recruitment in a murine model of cutaneous arthusreaction. Am J Pathol 176: 259-269.

Henderson LM, Figueroa CD, Muller-Esterl W, Bhoola KD (1994) Assembly of contact-phase factors on the surface of the human neutrophil membrane. Blood 84: 474-482.

Hong J, Andersson J, Ekdahl KN, Elgue G, Axen N, Larsson R, Nilsson B (1999) Titanium is a highly thrombogenic biomaterial: Possible implications for osteogenesis. Thromb Haemost 82: 58-64.

Hong J, Azens A, Ekdahl KN, Granqvist CG, Nilsson B (2005) Material-specific thrombin generation following contact between metal surfaces and whole blood. Biomaterials 26: 1397-1403.

Hong J, Ekdahl KN, Reynolds H, Larsson R, Nilsson B (1998) A new in vitro model study interaction between whole blood and biomaterial. Studies of platelet and coagulation activation and effect of the aspirin. Biomaterials 20: 603-611.

Jackson SP (2007) The growing complexity of platelet aggregation. Blood 109: 5087-5095.

Karp JM, Tanaka TS, Zohar R, Sodek J, Shoichet MS, Davies JE, Stanford WL (2005) Thrombin mediated migration of osteogenic cells. Bone 37:337-348.

Kilian O, Flesch I, Wenisch S, Taborski B, Jork A, Schnettler R, Jonuleit T (2004) Effects of platelet growth factors on human mesenchymal stem cells and human endothelial cells in vitro. Eur J Med Res 9: 337-344.
Laurens N, Koolwijk P, de Maat MP (2006) Fibrin structure and wound healing. J Thromb Haemost 4: 932939.

Li G, Ryaby JT, Carney DH, Wang H (2005) Bone formation is enhanced by thrombin-related peptide TP508 during distraction osteogenesis. J Orthop Res 23: 196-202.

Matowicka-Karna J, Kemona H, Dymicka-Piekarska V, Butkiewicz A (2006) Activation of blood platelets in echinococcosis - CD62p and CD63 expression. Parasitol Res 98: 214-217.

Mosesson MW (2005) Fibrinogen and fibrin structure and functions. J Thromb Haemost 3: 1894-1904.

Newball HH, Talamo RC, Lichtenstein LM (1975) Release of leukocyte kallikrein mediated by IgE. Nature 254: 635-636.

Nygren H, Tengvall P, Lundstrom I (1997) The initial reactions of $\mathrm{TiO}_{2}$ with blood. J Biomed Mater Res 34: 487-492.

Pagel CN, Sivagurunathan S, Loh LH, Tudor EM, Pike RN, Mackie EJ (2006) Functional responses of bone cells to thrombin. Biol Chem 387: 1037-1041.

Pagel CN, Song SJ, Loh LH, Tudor EM, Murray-Rust TA, Pike RN, Mackie EJ (2009) Thrombin-stimulated growth factor and cytokine expression in osteoblasts is mediated by protease-activated receptor- 1 and prostanoids. Bone 44: 813-821.

Park JY, Gemmell CH, Davies JE (2001) Platelet interactions with titanium: modulation of platelet activity by surface topography. Biomaterials 22: 2671-2682.

Ryaby JT, Sheller MR, Levine BP, Bramlet DG, Ladd AL, Carney DH (2006) Thrombin peptide TP508 stimulates cellular events leading to angiogenesis, revascularization, and repair of dermal and musculoskeletal tissues. J Bone Joint Surg Am 88 Suppl 3: 132-139.

Schwarz F, Wieland M, Schwartz Z, Zhao G, Rupp F, Geis-Gerstorfer J, Schedle A, Broggini N, Bornstein MM, Buser D, Ferguson SJ, Becker J, Boyan BD, Cochran DL (2009) Potential of chemically modified hydrophilic surface characteristics to support tissue integration of titanium dental implants. J Biomed Mater Res B Appl Biomater 88: 544-557.

Slater M, Patava J, Kingham K, Mason RS (1995) Involvement of platelets in stimulating osteogenic activity. J Orthop Res 13: 655-663.

Smith BR, Rinder HM, Rinder CS (2003) Interaction of blood and artificial surfaces. In: Thrombosis and Hemorrhage (Loscalzo J, Schafer AI, eds). Lippincott, Philadelphia, pp 865-900.

Song SJ, Pagel CN, Pike RN, Mackie EJ (2005) Studies on the receptors mediating responses of osteoblasts to thrombin. Int J Biochem Cell Biol 37: 206-213.

Stadlinger B, Lode AT, Eckelt U, Range U, Schlottig F, Hefti T, Mai R (2009) Surface-conditioned dental implants: An animal study on bone formation. J Clin Periodontol 36: 882-891.

Stanford CM (2010) Surface modification of biomedical and dental implants and the processes of inflammation, wound healing and bone formation. Int J Mol Sci 11: 354369. 
Tugulu S, Lowe K, Scharnweber D, Schlottig F (2010) Preparation of superhydrophilic microrough titanium implant surfaces by alkali treatment. J Mater Sci Mater Med 21: 2751-2763.

Wachtfogel YT, Kucich U, James HL, Scott CF, Schapira M, Zimmerman M, Cohen AB, Colman RW (1983) Human plasma kallikrein releases neutrophil elastase during blood coagulation. J Clin Invest 72: $1672-$ 1677.

Wang H, Li X, Tomin E, Doty SB, Lane JM, Carney DH, Ryaby JT (2005) Thrombin peptide (Tp508) promotes fracture repair by up-regulating inflammatory mediators, early growth factors, and increasing angiogenesis. J Orthop Res 23: 671-679.

Werner S, Grose R (2003) Regulation of wound healing by growth factors and cytokines. Physiol Rev 83: 835-870.

Wolberg AS (2007) Thrombin generation and fibrin clot structure. Blood Rev 21: 131-142.

$\mathrm{Xu} \mathrm{Z}, \mathrm{Xu} \mathrm{H}$, Ploplis VA, Castellino FJ (2010) Factor VII deficiency impairs cutaneous wound healing in mice. Mol Med 16: 167-176.

Zarbock A, Polanowska-Grabowska RK, Ley K (2007) Platelet-neutrophil-interactions: Linking hemostasis and inflammation. Blood Rev 21: 99-111.

Ziegler-Heitbrock HW, Ulevitch RJ (1993) CD14: Cell surface receptor and differentiation marker. Immunol Today 14: 121-125.

\section{Discussion with Reviewer}

Reviewer II: Could you please comment on the impact of alkali treatment on the use of other clincically relevant metals like tantalum?

Authors: Kokubo and colleagues intensively investigated the effect of alkali- and heat-treatment on tantalum surfaces (Kato et al., 2000; Miyazaki et al., 2000; Miyazaki et al., 2001, see "Additional References"). They showed that, in vitro, alkali-treated Tantalum surfaces could form apatite in a short period of time (compared to native tantalum surfaces), hence have a higher bone-bonding potential (Miyazaki et al., 2000). They showed in another study that subsequent heat treatment leads to higher mechanical surface stability (of the alkali-treated implant) without decrease in its bioactivity (Miyazaki et al., 2001). An in vivo study where native and heat- and alkali-treated tantalum plates were implanted into rabbit tibiae showed that heat- and alkali- treated tantalum implants showed a much greater bone bonding compared native ones (Kato et al., 2000). The bioactivity was credited to the alkalitreatment which was stabilized by heat treatment. Although no in vivo study with alkali-treated tantalum (without subsequent heat treatment) has been performed, those studies show that alkali treatment on tantalum surfaces lead to a improved bone formation at the implant interface.

Reviewer II: It is argued that the topography of the SBA samples does not change with reference to Tugulu et al. (2010) (text reference). First of all, I cannot find evidence of no topographical changes in that paper (e.g., AFM or similar). Furthermore, if true, it would have been important to have a flat-polished-titanium control +/- alkali treated. Authors: Comparable SEM analysis has been performed after exposure of partially heparinized whole blood on polished Ti-surfaces. The result in terms of surface coverage followed similar trends demonstrated for SBA samples. (cf. Fig. 10). In details, increased coverage was observed on alkali-treated surfaces compared to non-treated surfaces, and the coverage increased with longer incubation time (Fig. 10A-D). As well fibrin fiber formation was observed on alkali-treated polished surfaces (Fig. 10F), while no fibers were observed on non-treated polished surfaces (Fig. 10E). For our applications as endosseous implants polished titanium surfaces are not relevant; therefore, only SBA surfaces have been further investigated.

\section{Additional References}

Kato H, Nakamura T, Nishiguchi S, Matsusue Y, Kobayashi M, Miyazaki T, Kim HM, Kokubo T (2000) Bonding of alkali- and heat-treated tantalum implants to bone. J Biomed Mater Res 53: 28-35.

Miyazaki T, Kim HM, Kokubo T, Miyaji F, Kato H, Nakamura T (2001) Effect of thermal treatment on apatiteforming ability of $\mathrm{NaOH}$-treated tantalum metal. J Mater Sci Mater Med 12: 683-687.

Miyazaki T, Kim HM, Miyaji F, Kokubo T, Kato H, Nakamura T (2000) Bioactive tantalum metal prepared by $\mathrm{NaOH}$ treatment. J Biomed Mater Res 50: 35-42. 